\title{
Hiding or Helping? \\ Determinants and Consequences of the Timing of Earnings Conference Calls
}

\section{By: Sudipta Basu and Zhongnan Xiang}

\begin{abstract}
Open conference calls are an important information source because of their forward-looking discussion, interactive nature, and easy accessibility. Using Bloomberg data, we investigate why firms time earnings conference calls differently and how the stock market interprets and reacts to firms' timing choices. We directly measure retrospective and prospective news that derives from earnings calls by earnings surprise and the tone of forward-looking statements. We find that firms with more extreme news (both good and bad) tend to hold calls outside trading hours, especially in the evening. To test whether the market understands the information of "timing," we conduct an event study around the date when firms schedule the calls. We find a higher trading volume when the market is notified of an upcoming switching from outside to during trading hours. Overall, our results suggest that firms strategically time conference calls and investors infer news from the timing.
\end{abstract}

Keywords: Information asymmetry, litigation risk, market liquidity

JEL codes: G14, K22, M41 


\section{Introduction}

The goal of this paper is to study the strategic timing of the earnings conference call. We investigate two questions: (1) why do firms hold conference calls differently, as some hold during regular trading hours whereas others do so after trading hours, and (2) how do investors interpret and react to firms' call timing choices? The passage of Regulation Fair Disclosure in 2000, along with improved means of communication, increased the frequency of open conference calls with investors and analysts. Prior research documents higher price volatility and trading volume around calls and less post-earnings-announcement drift after calls, suggesting the informativeness of these calls (e.g., Bushee, Matsumoto, and Miller, 2004; Kimbrough, 2005). Future-oriented discussions and in-person communication between managers and analysts further increase the informativeness and importance of conference calls (Matsumoto, Pronk, and Roelofsen, 2011). Because there is less trading after hours than during regular hours, some firms might hold earnings calls after hours to avoid public scrutiny on the disclosure or to give the market time to digest new data. As such, we explore firms' decisions to hold their conference calls either during regular trading hours or after trading hours and how the stock market reacts to these choices.

Firms usually hold conference calls closely (i.e., within two trading days) after announcing earnings. Despite their similarities, earnings calls and earnings released have key differences. Managers disclose disaggregated earnings information and outlook for firms' future financial performance during earnings calls, which are highly related to the earnings release. However, managers spend a lot of time on the two-way interaction with investors and analysts during earnings calls, which contrasts with the distinct one-way communication to the users of financial information typical of earnings releases. 
Prior studies have found that managers are more likely to release bad earnings after trading hours (e.g., Patell and Wolfsen, 1982). However, in recent years, almost all firms have begun to announce earnings after trading hours regardless of earnings information (e.g., Doyle and Magilke, 2009). One explanation for this change in behavior is that informed traders who actively follow the firm and better understand the implications of earnings are more likely to trade after hours, thereby rendering the price discovery process more efficient (Jiang, Likitapiwat and McInish, 2012). A similar timing pattern would be expected for conference calls given their informativeness to the market. Hence, we explore whether earnings call timings are similar to those of earnings releases.

Notably, we observe higher variation in the data of call timings throughout the day. In our sample, around $25 \%, 35 \%$, and $40 \%$ of firms hold earnings conference calls before, during and after trading hours, respectively. Furthermore, firms switch the call timings more often than the timings of the press release. More than $75 \%$ of firms have switched the timing slots of conference calls (i.e., before, during, and after trading hours), and around $60 \%$ of firms have multiple switches during our sample period. The relatively rich variation in the cross-section and time-series indicates managers' strategic choices of when to schedule earnings calls, and provides us an ideal setting in which to study firms' strategic timing behaviors.

Next, we expect that managers strategically schedule conference calls as often as, if not more frequently than, earnings releases. First, the interactive nature of calls lets audience members directly question managers. The Q\&A session reveals analysts' private information when they ask questions and managers' private information when they respond (Matsumoto and Roelofsen, 2011). If conference calls are a rich information medium, managers likely have incentives to schedule them carefully. Additionally, the use of natural language during conference calls lets managers 
steer the conversation. Compared to earnings releases wherein managers choose what to disclose, in conference calls they also decide how to disclose (Price, Doran, Peterson, and Bliss, 2012). In this sense, the potential benefits of strategically timing conference calls are higher.

Two competing theories offer explanations for why some firms hold calls after trading hours: (1) firms try to hide bad news by reducing media exposure and public scrutiny; and (2) managers help investors understand complex data by giving them more time to collect and evaluate data. Jenter (2005) and Michaely, Rubin and Vedrashko (2016) find that hiding bad news is associated with a longer post-earnings-announcement drift and increased insider trading, suggesting possible private benefits of after-hours disclosure. Doyle and Magilke (2009) find that disclosure timing does not induce different market reactions and that more complex firms tend to announce earnings in the evening. We analyze how information derived from conference calls impacts firms' timing choices to help identify their "hiding" or "helping" motives.

We collect timestamps for earnings release and conference calls from Bloomberg. To analyze firms' timing decisions, we partition each event into three groups-before-market-open (from midnight to 9:30 a.m., hereafter BMO) events, regular-trading-hour (from 9:30 a.m. to 4 p.m., hereafter RTH) events, and after-market-close (from 4 p.m. to midnight, hereafter AMC) events. We measure backward-looking and forward-looking news derived from conference calls by the earnings surprise of the current quarter and the tone of future-oriented statements (e.g., we aim to, we expect that) made during calls, respectively. Using an ordered logit model, we find that both types of news impact timing choices: firms with more extreme news (either good or bad) tend to hold conference calls outside regular trading hours, with the most extreme news being released after the market closes. We use a system of equations to model the timing choices of earnings releases and conference calls together and show that firms with worse earnings tend to announce 
the news in the evening while firms with more substantial unsigned news likely schedule the calls after the market closes.

To analyze the stock market reaction to the timing itself, we hand collect the date when firms announce their schedule for conference calls, which marks investors' first exposure to the timing information. We find that the trading volume around the "scheduling" event is higher when the market is notified of that a conference call was moved from regular trading hours to outside of trading hours. This finding provides some evidence that investors infer future uncertainty beyond the time switching. The results are more prominent for firms that have multiple call timing switches during the sample period, suggesting that investors interpret the timing news more carefully for firms that likely schedule the events strategically.

This paper contributes to the existing literature in several important aspects. We extend research on voluntary disclosure by showing that firms strategically time their earnings conference calls. Because future-oriented discussions during conference calls increase the informativeness of the events (Matsumoto and Roelofsen, 2011), we separate the information derived from calls into backward-looking and forward-looking pieces and directly measure the two components. Our results provide evidence that firms help the market digest more complex news through conference calls. We also simultaneously model the timings for the earnings announcements and earnings conference calls and show different mechanisms for firms to schedule the two events: firms time press releases based on signed earnings news, whereas they time conference calls based on the magnitude of the unsigned information.

Next, our methodology develops more powerful tests to identify whether and how investors react to the timing information. Post-announcement drift is often used to draw inferences on market consequences of strategic timing behaviors. For example, a more substantial drift after earnings 
announcements on Friday evenings indicates an incomplete and delayed market reaction to such events. These studies consider news heterogeneity across timing slots, rather than pure timing information, as factors to drive the long-run market reaction. Instead, we hand collect and develop a novel dataset of firms' press release to schedule earnings calls, which is the first time that investors are aware of such "timing" information. Since firms disclose the timing information only in such press releases without any fundamental inferences, the market reaction around the scheduling date could be attributable to the timing by itself. By examining the trading volume around such scheduling press releases, we find a significant market reaction when firms announce a switch of the timing of their conference calls.

Beyond these findings, we also use and validate Bloomberg timing data, which has been rarely used in accounting research. We verify the conference call time data provided by Bloomberg at a minute level using firms' press releases and such newswires as LexisNexis and Seeking Alpha. Over $99 \%$ of the timestamps can be verified. We then compare the timestamps for earnings release in Bloomberg and $\mathrm{I} / \mathrm{B} / \mathrm{E} / \mathrm{S}$ and find that Bloomberg delivers more accurate time data. When researching earnings announcements, prior studies often use I/B/E/S data as a starting point and correct the data based on various news sources. We suggest that Bloomberg provides credible data without further verification.

In the next section, we discuss prior studies and develop hypotheses. Section 3 compares Bloomberg and I/B/E/S timing data and describes the sample selection process. Section 4 outlines the research designs and discusses empirical results. The final section concludes.

\section{Prior Research and Hypothesis Development}

\subsection{Earnings conference calls}


Managers hold conference calls with market participants to provide additional qualitative and contextual information. During a typical earnings conference call, key executives first present quarterly performance data, and the following discussion is driven by questions from analysts and investors (National Investor Relations Institute [2014]). Heinrichs, Park, and Soltes (2018) report a high demand for conference calls from institutional investors, sell-side analysts, and even investors who do not hold a position in the firm.

Conference calls may provide incremental information to earnings releases for several reasons. A survey by the Association for Investment Management and Research (AIMR [2000]) highlights the importance of corporate executives themselves as human capital information. The presentation session helps investors know the firms' key executives better, and the amount of communication during calls among executives reveals the relative location of knowledge within a management team (Li et al. 2014). In addition to managers' disclosure, which is the only focus for most disclosure formats, conference calls also contain non-scripted information in the form of Q\&As with audience members such as sell-side analysts (Matsumoto et al., 2011). Moreover, conference calls provide "soft" information, including the order, tone, and vocal cues of the speakers (Price et al., 2012; Davis et al., 2015).

Regulation Fair Disclosure (Reg FD), passed in 2000, was intended to reduce private communications between managers, large investors, and analysts, which gave larger investors an information advantage over small investors. Early studies on closed (i.e., by invitation only) earnings conference calls before Reg FD find that firms with less informative financial statements are more likely to host such calls (Tasker 1998; Frankel et al. 1999). Frankel et al. (1999) also establish that earnings calls convey material information, as evidenced by unusually high stock return volatility and trading volume during the call. 
Much research has examined open (to everyone) conference calls after Reg FD, which forced a switch from closed calls. Bushee et al. $(2003,2004)$ provide evidence that earnings calls contain incremental information over the earnings release and move the market. Lansford et al. (2009) find that firms disclose a non-trivial amount of management guidance exclusively in conference calls, indicating calls as a significant disclosure channel. Matsumoto et al. (2011) use intraday return data to show that both the presentation and Q\&A sessions are incrementally informative, with the Q\&A sessions more informative than management discussion sessions. Kimbrough (2005) and Price et al. (2012) report that open conference calls induce price volatility, trading volume, and post-earnings-announcement drift. Brochet, Kolev, and Lerman (2018) find a co-movement of stock return over the conference call windows of announcing firms and their industry peers, suggesting information transfer during calls. Overall, earnings conference calls reveal fairly much information and are able to move the market.

The way managers present and answer questions during calls affects how investors understand earnings news. Hollander, Pronk, and Roelofsen (2010) find that managers sometimes do not answer questions and withhold information during conference calls; moreover, investors interpret the silence negatively. Gow, Larcker, and Zakolyukina (2019) construct a linguistic measure of "non-answers" to flag when a manager does not respond to questions during conference calls. They provide evidence that the level of disclosure is associated with proprietary costs, external financing needs, and legal liability. Price et al. (2012) find that managers' linguistic tone during calls predicts abnormal returns and trading volume and that the tone explains post-earnings announcement drift better than earnings surprise. Larcker and Zakolyukina (2012) use a linguistic model to classify conference calls as "truthful" or "deceptive" and show that these labels predict accounting manipulation better than or as well as models based on financial variables. 
Conference calls are also informative to analysts, as evidenced by their active participation (Call et al., 2017; Jung et al., 2018). Analysts release their forecasts more quickly and are more accurate after firms hold open conference calls (Bowen, Davis, and Matsumoto, 2002; Lansford et al., 2009). Mayew, Sharp, and Venkatachalam (2013) argue that these associations are more significant for analysts that ask questions during conference calls than for nonparticipating analysts. Call, Sharp, and Shohfi (2017) find that buy-side analyst attendance during calls is associated with subsequent decreases in sell-side coverage and an immediate drop in the firms' stock return, suggesting some real impact of conference calls on both analysts and investors.

To the best of our knowledge, these papers do not document timing patterns of earnings conference calls and the factors that impact the timings. The most relevant paper we found is Chen, Demers, and Lev (2019). They show that the tone of earnings calls becomes much more negative as the day wears on. They attribute this hour-by-hour change to mental and physical fatigue during the day and provide evidence on different psychological features across the timings of calls. Our focus is different: we examine if managers schedule conference calls based on the earnings news.

\subsection{Strategic timing}

Managers strategically time market entry (Schoenecker and Cooper, 1998), new technology adoption (Stenbacka and Tombak, 1994), going public (Benninga, Helmantel, and Sarig, 2005), buying back shares (Brockman and Chung, 2001), and many other activities. Accounting researchers document that firms often release bad news after the major stock exchanges close. Patell and Wolfson (1982) report that firms disclose good news more often during the day but disclose bad news more often in the evening. They posit two possible reasons: (1) managers try to hide bad news by reducing media exposure; and/or (2) managers give the market more time to evaluate and assimilate bad news. Empirical studies (Francis, Pagach, and Stephan, 
1992; Doyle and Magilke, 2009; DeHaan, Shevlin, and Thornock, 2015; Michaely et al., 2016) examine different sample periods and find that firms disclose bad news after the market closes.

Although the systematic timing of earnings announcements is well documented, the reasons are not fully understood. Gennotte and Trueman (1996) provide theoretical evidence supporting the argument that managers who maximize the firm's post-announcement price disclose negative earnings news when the market cannot trade. Hirshleifer et al. (2009) show that investors get distracted after the market closes due to limited attention. Both papers argue that managers should release bad news after trading hours, consistent with Patell and Wolfson's "hiding" interpretation.

The empirical evidence is mixed. DellaVigna and Pollet (2009) document a "Friday evening" impact and show that Friday earnings announcements are followed by less immediate response and more drift. Michaely et al. (2016) argue that the strategic release of bad earnings news after trading hours brings firms benefits through reduced market scrutiny and delayed market response. They also show that firms switching earnings releases to evenings (Friday evenings) have larger (the largest) post-announcement drift and more (the most) insider trading. However, DeHaan et al. (2015) find negative returns when the market is notified of an upcoming Friday after-market earnings release, suggesting that investors infer forthcoming bad news and are not entirely fooled by announcement timing. Their findings contradict Patell and Wolfson's first argument. Doyle and Magilke (2009) focus only on firms that switch their announcement timing and find no evidence that managers opportunistically disclose worse news after the market closes or on Fridays. They argue instead that the reason to disclose after trading hours is that those firms are more complex, consistent with Patell and Wolfson's "helping" interpretation.

\subsection{Hypothesis development}


We seek to examine the strategic timing of earnings conference calls. On the one hand, as an informative public event, managers have incentives to strategically time conference calls following the logic of timing earnings announcements. On the other hand, compared with the oneway information flow in an earnings release, the interactive nature of conference calls gives managers more discretion to shape analyst and media narratives. Furthermore, we observe a greater variation of timing choices in both cross-section and time-series within conference call data than press release data. We expect that our setting is ideal for testing firms' strategic timing behaviors.

Following Patell and Wolfson's (1982) "hiding" argument, along with theoretical (Gennotte and Trueman, 1996; Hirshleifer et al., 2009) and empirical evidence (Francis, Pagach, and Stephan, 1992; Michaely, Rubin and Vedrashko, 2016), we predict that firms are more likely to hold conference calls after trading hours than during trading hours if they release more negative news. Following the same logic, in an attempt to reduce market scrutiny and delay market response, firms are even more likely to hold AMC conference calls to present and discuss negative news.

Hla: Firms with more negative earnings news are more likely to hold after-hour (especially AMC) conference calls.

Following Patell and Wolfson's (1982) "helping” argument, along with other empirical evidence (Doyle and Magilke, 2009; DeHaan et al., 2015), we predict that firms with more complex information are more likely to hold conference calls after trading hours. A typical conference call provides interpretations of past performance and management guidance (Matsumoto et al., 2011; Lansford et al., 2009); we believe the complexity comes from both backward-looking and forward-looking information. As actual earnings deviate from the consensus estimate, managers will put more effort into explaining the surprise. Likewise, the more future-oriented discussions are given during the conference call, the more time investors will need 
to digest the news. Bozanic, Roulstone, and Van Buskirk (2017) document that all forward-looking statements, both quantitative or qualitative, generate significant investor and analyst responses. Because AMC calls give the market even more time to understand and evaluate news than those held in the morning, we further predict that the results will be stronger for AMC calls than BMO calls. We state the hypothesis as follows.

H1b: Firms with more complex earnings news are more likely to hold after-hour (especially AMC) conference calls.

If managers strategically time conference calls, investors will understand and react to the call timing itself under the efficient market assumption. Many studies show that the market is remarkably efficient, especially given the increasing percentage of high-frequency traders (e.g., Malkiel, 2003; Brogaard, Hendershott, and Riordan, 2014). Though over $70 \%$ of firms in our sample have switched the timing of conference calls, switching behaviors themselves are rare. The relatively sticky timing choices likely make the switches noticeable when scheduled. If investors infer the news beyond the timing, we expect a strong market reaction when firms announce an upcoming timing switch of conference calls.

Following Patell and Wolfson's "hiding” argument, and consistent with $\mathrm{Hla}$, we expect a negative market reaction when investors are aware of an upcoming call switching from RTH to BMO, from RTH to AMC, or from BMO to AMC, and vice versa. Following their "helping" argument, and consistent with $H 1 b$, we expect that the market reaction will be more volatile, and the trading volume will be higher when investors are notified of the above switches, and vice versa. We state the two hypotheses for market reactions as follows.

H2a: The market reaction will be more negative when firms announce a switch of conference call timing from RTH to BMO, from RTH to AMC, or from BMO to AMC, and vice versa. 
H2b: The trading volume will be higher when firms announce a switch of conference call timing from $R T H$ to $B M O$, from $R T H$ to $A M C$, or from $B M O$ to $A M C$, and vice versa.

Among the firms that ever switched the timing of conference calls, some firms switch only once and stick to the new schedule afterward. However, some switch multiple times during the sample period. We expect that these firms are more likely to schedule the calls discretionary and strategically; investors will infer the news better beyond the repetitive "switching" behaviors. Moreover, investors will better understand the information inferences of timing when firms announce the schedule close to the calls. Boulland and Dessaint (2017) document that firms release "Notice of Earnings" 10 days before the news events on average. If the interval between the "notice" and the events is short, managers may understand firms' performance more thoroughly and likely schedule the calls based on such knowledge. The short interval will also make it easier for investors to infer earnings news. Therefore, we expect a stronger market reaction of timing switches when firms have multiple switches, and when firms announce the "switching" close to the calls.

H3: The association in $\mathrm{H} 2$ will be stronger when firms have multiple switches during the sample period, and/or when the "scheduling" announcements are close to conference calls.

\section{Sample selection and summary statistics}

\subsection{Sample selection}

We seek to reliably identify the timestamps of both earnings releases and conference calls. We start from Bloomberg time data of conference calls and verify the timestamps by using firms' press releases $^{1}$ and such newswires as Nexis Uni (formerly LexisNexis) and Seeking Alpha. Panel

\footnotetext{
${ }^{1}$ Firms usually announce the minute-level time date of conference calls in earnings releases.
} 
A of Table 1 presents the verification process. We first download 157,214 earnings conference calls from Bloomberg, spanning from 2008 to 2017. We begin the sample period in 2008 because Bloomberg's minute-level time data are not in a readable format before that year. Over these calls, 123,403 can be assigned with an identifier (e.g., ticker, cik, gvkey, or permno), which helps us to link these calls to other databases. Among them, 115,715 and 67,661 calls can be identified from different sources at date level and minute level, respectively. ${ }^{2}$ We corroborate almost all (i.e., 99.93\%) the call dates. Additionally, more than $99 \%$ of the records with an exact hour and minute can be verified by at least one of the other sources. These ratios indicate that Bloomberg is a credible database for the time of conference calls.

Bloomberg provides time data on earnings releases as well. At the same time, $\mathrm{I} / \mathrm{B} / \mathrm{E} / \mathrm{S}$ is a commonly used data source for earnings announcement timings, which could be used to construct paired events with Bloomberg timestamps for conference calls. ${ }^{3}$ We compare the accuracy of firms' earnings announcement time from the two data sources, as summarized in Panel B of Table 1. We first match each earnings announcement from Bloomberg with an $\mathrm{I} / \mathrm{B} / \mathrm{E} / \mathrm{S}$ announcement within a seven-day window. This fuzzy match reveals 128,539 records. The time data from the two sources is consistent for 112,571 observations, which we assume indicates a correct record. Of the 15,968 remaining cases, 1,816 have inconsistent dates, and 14,152 have inconsistent times (exact hour and minute). We manually corroborate the timestamps using the firms' official websites and such newswires as Wall Street Journal, Dow Jones News, and Nexis Uni. Among the 1,816 cases with inconsistent date information, 1,134 cases can be verified from the above sources; Bloomberg

\footnotetext{
${ }^{2}$ Most firms disclose the date of earnings conference calls in their concurrent earnings release or call transcripts. Only some of them reveal the exact hour and time of calls at a minute level with clear time zone information. Therefore, we get fewer observations for verification at a minute level than at a date level.

${ }_{3}^{3}$ Bradley et al. (2014), Michaely et al. (2016), and DeHaan et al. (2015) all find errors in I/B/E/S timestamps of earnings announcements. When conducting research, they start from $\mathrm{I} / \mathrm{B} / \mathrm{E} / \mathrm{S}$ data and verify the timestamps using newswires.
} 
offers the correct announcement date in $86 \%$ (975) of cases. We then identify 1,472 records out of 14,152 records with inconsistent time information. ${ }^{4}$ Bloomberg provides the correct time for $82 \%$ $(1,203)$ of cases. This comparison indicates Bloomberg as a relatively accurate, if not perfect, database for the time of earnings release.

Panel C of Table 1 presents the sample selection process. Since Bloomberg offers reliable time data for both earnings announcements and conference calls, we start with 99,790 paired events from 2008 through 2017 with complete timing information. ${ }^{5}$ We first drop 17,988 calls held by firms from the financial industry. We remove observations with missing data on one of our key independent variables, earnings surprise, eliminating 5,597 cases that lack I/B/E/S earnings data. Since we analyze the tone of forward-looking statements, we discard 4,931 observations with no identifiable conference call transcripts. Next, we drop 971 and 745 records, respectively, due to missing control variables when merging with Compustat and Thomson Reuters. We further lose 631 cases with the stock price lower than $\$ 1$, leaving a sample of 68,981 observations from 3,295 unique firms. We use this sample to summarize firms' timing patterns of earnings announcements and conference calls.

Since we study firms' strategic timing behaviors and examine the factors that will impact firms' timing choices, we require that firms switch the timing of conference calls at least once in our sample period. This step removes 22,293 records, leaving 46,688 observations to test H1. ${ }^{6}$ To analyze the market reaction to the timing itself, we collect the time when firms announce the

\footnotetext{
${ }^{4}$ Because of the large amount of data we need to hand collect, we pick only 4,246 records from three years (we randomly select the year 2010, 2014, and 2018) and conduct manual verification. We could only verify 1,472 out of 4,246 cases given the fact that firms do not often disclose exact hour and minute of earnings releases.

${ }^{5}$ We require that conference calls be held within the range of $[0,2]$ days around the earnings announcements.

${ }^{6}$ Our results for $\mathrm{H} 1$ are robust if we use the larger sample, including firms that never switch the timing of calls $(68,981$ observations from 3,295 firms).
} 
schedule of conference calls. We eliminate the observations without identifiable press release of “scheduling." We are left with 44,488 records to test $\mathrm{H} 2$ and $\mathrm{H} 3$.

\subsection{Timing patterns of earnings announcements and conference calls}

Table 2 provides an overview of the intra-week and intra-day distribution of earnings release and conference call timings. The timing of conference calls is highly correlated with the timing of earnings releases indicated by a high concentration of diagonal numbers. Firms often hold earnings calls within one business day after the earnings release (e.g., for an earnings release in the morning, the conference call is usually held before the next morning). In general, firms are less likely to hold conference calls on Monday and Friday than on Tuesday, Wednesday, or Thursday. Specifically, 0.04\% (27 out of 68,981) of firms hold conference calls on Friday evening, which is the lowest among all intra-day and intra-week combinations of call timing. The proportion is even lower than that of the firms announcing earnings on Friday evenings $(0.2 \%)$, indicating that managers are reluctant to hold conference calls on Friday evenings.

Regarding the intra-day distribution, firms always release earnings outside of trading hours, whereas they hold conference calls more evenly across the three slots (i.e., BMO, RTH, and AMC). Figure 1 depicts the timing slots of the two events from 2008 to 2017. Within our sample period, slightly more firms announce earnings in the morning than in the evening, whereas very few firms (around $0.5 \%$ on average) announce earnings during regular trading hours. However, the ratio of firms holding calls during the three slots changes more drastically. We find that $35 \%$ of firms hold earnings calls during trading hours in 2017, although this percentage fell over our sample period. Meanwhile, 30\% and 35\% of firms held BMO and AMC earnings calls in 2017, respectively. Figure 2 presents the conference call timings by 30 minutes. The most popular time for firms to announce earnings is right after the market closes; over $40 \%$ of firms send out their earnings 
announcements from 16:00 to 16:29. Conference call schedules are not as clustered: firms often start their conference calls from $16: 30$ to $17: 29$ or from $8: 30$ to 11:29. There are also some firms initiating conference calls during afternoon market hours.

Table 3 investigates firms switching behaviors of the two events. As shown in Panel A, firms often stick to the previous quarter timing choices for both events. Firms change the timing slots of earnings calls more often than press releases. The switches happened the most in 2008, indicating that firms likely change disclosure schedules when they experience drastic fundamental changes. After a severe drop in switching for both events in 2009, firms began to switch the timing of conference calls more frequently while shifting the timing of earnings releases less frequently. Notably, they significantly increase the frequency of changing the timings of calls only without changing the schedules of earnings releases. Figure 3 plots this trend of firms' switching behaviors for one of the events only. In 2017, the frequency of firms that shift only the timing of calls was more than twice that of firms switching only the schedule of earnings releases.

Although switching behaviors are not common in our sample, most firms have at least one switch in our sample period, as presented in Panel B of Table 2. Only 22\% of firms are strictly "sticky" (i.e., always announcing earnings and initiating conference calls within the same timing slot). ${ }^{7}$ We find that 1,880 and 2,306 out of 3,295 firms have ever switched the timing slots of press releases and conference calls. Panel C of Table 3 presents data on how often firms schedule their earnings calls in a different time slot within adjacent quarters. Among the three slots of timing, firms holding BMO calls are most likely to change in the next quarter: $12.57 \%$ of firms holding

\footnotetext{
${ }^{7}$ Bushee et al., (2004) and Chen et al., (2019) both document the sticky call timing choices. Managerial decisions are often sticky (e.g., cost stickiness, dividends smoothing). Guttman, Kadan, and Kandel (2010) find that over 25\% of firms did not change their dividends payout ratio over the 40-year period 1966-2005. Understanding such stickiness, the information content of the payout policy is still widely discussed (e.g., Healy and Palepu, 1988; Koch and Sun, 2004).
} 
BMO calls switch to during or after trading hours in the next quarter, whereas the switching percentage is around 7\% for firms holding RTH and AMC calls in the current period.

\subsection{Variable definitions}

Since managers provide interpretations of past performance and management guidance during conference calls (Matsumoto et al., 2011; Lansford et al., 2009), we separate the news derived from a conference call into backward-looking and forward-looking pieces. We directly measure these two pieces with earnings surprise and the tone of forward-looking statements, respectively. To test our first set of hypotheses, we examine both the direction (the favorability of the earnings news) and magnitude (the complexity of the earnings news) of the information content. We follow prior studies and define earnings surprise as the difference between announced earnings per share and the median latest analyst forecast as reported by $\mathrm{I} / \mathrm{B} / \mathrm{E} / \mathrm{S}$, normalized by the stock price at the beginning of the quarter (e.g., Livnat and Mendenhall, 2006; Michaely et al., 2016).

We use a textual measure to proxy for the forward-looking news from earnings calls. Since managers prepare or even pre-record the presentation sessions but cannot fully expect the questions during Q\&A sessions, we believe that only the information derived from the presentation sessions will impact firms' timing choices. Hence, we build our textual measures based on the presentation sessions of call transcripts. ${ }^{8}$ First, we follow Bozanic et al. (2017) and classify sentences in a conference call as forward-looking if they include at least one prospective term, such as "we expect" or "is anticipated." Appendix A presents a full list of forward-looking phrases. ${ }^{9}$ Next, we examine the "positivity" of each forward-looking statement by taking the ratio of positive words in the

\footnotetext{
${ }^{8}$ All of our results are consistent if the textual-based measures are constructed using the full transcripts.

${ }^{9}$ We remove all the sentences by operators, and this removal process is the same when we construct the uncertainty measure.
} 
sentence. ${ }^{10} \mathrm{We}$ calculate average "positivity" and use the value as the tone of forward-looking statements.

We also consider other information characteristics that may impact firms' call-timing strategies, such as uncertainty and the focus of forward-looking statements. We measure the uncertainty level of news using a similar sentence-by-sentence based approach. We take the ratio of uncertain words in a sentence and obtain the "uncertainty" score of each sentence in the presentation session of the conference call. We then get the average score of "uncertainty" throughout the text. Bozanic et al. (2017) document that future-oriented statements generate a significant market response; we propose that managers will consider the weight of forward-looking statements as an essential factor to schedule conference calls during or outside trading hours. We define this measure as the ratio of forward-looking statements within the presentation session of the call. At the summary statistics level, we also construct such textual-based measures as the length of full conference calls, the length of presentation sessions, the number of executive participants and analyst participants, the ratio of answers to questions, etc.

To test our second set of hypotheses, we hand collect the date when firms announce the schedule for conference calls and perform an event study on this "scheduling" date. We measure the market reaction of the timing information with a 3-day cumulative abnormal return (CAR), constructed using Fama-French (2015) 5-factor models. ${ }^{11}$ We use the natural log of trading volume for the same window as the unsigned market reaction measure. Throughout the analysis, we control for seven firm characteristics: firm size, market-to-book asset ratio, financial leverage, sales

\footnotetext{
${ }^{10}$ We remove all the common stop words before calculating the ratio. The process is the same when we calculate uncertainty ratio sentence by sentence.

${ }^{11}$ We also use CAPM and Carhart momentum models to construct CAR as robustness check and the results remain consistent.
} 
growth, number of analysts following the firm, the dispersion of analyst forecasts, and institutional ownership percentage. Appendix B provides detailed definitions for all the variables.

\subsection{Summary statistics}

Table 4 provides summary statistics using two samples. One is the full sample of 68,981 conference calls from 3,295 unique firms. The other is the smaller sample of 46,688 firm-quarter observations from firms that have ever switched the timing of conference calls during the sample period, which we also use for subsequent regression analysis. Because we divide firms' timing choices into three groups - before the market opens, during regular trading hours, and after the market closes, we summarize the characteristics of conference calls and firm fundamentals among these three groups. We winsorize the top and bottom $1 \%$ of the continuous variables to mitigate the potential effect of outliers.

We show similar statistics among the two samples in columns (1) to (6). Regarding the information coming out from conference calls (Panel A), earnings surprise is highest for AMC calls, then BMO calls, and finally, RTH calls. The ranking is opposite for the tone of futureoriented discussions during the presentation sessions of earnings calls. The results in a univariate level reject $\mathrm{Hla}$ since firms discuss the most positive earnings news during AMC earnings calls. The unsigned backward-looking and forward-looking news (i.e., the absolute value of the previous two variables) show a significant difference among the three types of calls. The comparison indicates that earnings calls outside regular hours (especially AMC calls) contain more complex information, which supports $H 1 b$. Actual earnings also impact the firms' timing decisions. The mean of actual earnings is around zero for AMC calls, whereas it is positive for the other two groups with the value for the RTH group slightly higher. 
In terms of the tone throughout the conference call, we find a more negative tone as the day wears off, which is consistent with the findings in Chen et al. (2019). Regarding the uncertainty of managers' speech, we do not find a difference among the three groups at a univariate level. Besides textual measures, we also summarize other general characteristics of conference calls in Panel B. We find that the length of calls, the length of presentation sessions, the ratio of answers to questions, and the number of managers participating are similar among the calls held during different timing slots. The AMC calls are associated with the highest weight of forward-looking information, while BMO calls are associated with the most analysts attending the events.

We present firm-level characteristics in Panel C. Firms holding calls in the evening have lower monitoring compared to the other two groups, measured by firm size, debt financing, and institutional ownership. On the contrary, firms with a larger size, higher leverage, more analyst following, and higher institutional holdings are more likely to hold conference calls in the morning. Moreover, firms that hold AMC calls are associated with the highest market-to-book asset ratio, lowest analyst coverage, and lowest forecast dispersion among analysts.

We also separate our sample into firm-quarters with and without switching call timings and show the statistics in columns (7) through (9). Compared with the observations sticking to the previous call timings, switching behaviors are, on average, associated with more negative news, both backward-looking and forward-looking. Interestingly, more managers attend the calls but fewer analysts attending when firms switch the timing. Regarding firms' fundamentals, switching from regular trading hours to outside trading hours is associated with smaller firm size, whereas switching the other way around is associated with higher leverage. Firms also tend to shift the call timing when they have higher sales growth and lower market-to-book ratio. 


\section{Research design and empirical results}

\subsection{Determinants of conference call timing: multinomial logistic approach}

We use a multinomial logistic regression to model firms' choices to hold conference calls during different timing slots. Since "hiding" and "helping" hypotheses have different implications on firms timing practice, we explicitly model the asymmetric relation as follows:

$$
\begin{aligned}
\log \frac{\operatorname{Prob}\left(t_{\_} \text {call }=j\right)}{\operatorname{Prob}\left(t_{\_} \text {call }=R T H\right)}= & \beta_{0}+\beta_{1 j} \text { Surprise }+\beta_{2 j} N D_{1}+\beta_{3 j} N D_{1} \times \text { Surprise }+\beta_{4 j} \text { Tone FLS }+ \\
& \beta_{5 j} N D_{2}+\beta_{6 j} N D_{2} \times \text { Tone FLS }+\Sigma \beta_{k j} \text { Controls }_{k}+F E+\varepsilon
\end{aligned}
$$

where $t \_c a l l$ is an indicator variable that equals 0 if the firm holds an RTH conference call and equals 1 or 2 if the firm holds a BMO or AMC conference call, respectively. Because we build a log-odds ratio for $\mathrm{BMO}$ calls and AMC calls compared to the reference $\mathrm{RTH}$ call group, $j$ can only equal 1 or $2 . N D_{1}$ is an indicator that equals 1 if the earnings surprise is negative and 0 otherwise. $N D_{2}$ is an indicator that equals 1 if the tone of forward-looking statements is negative and 0 otherwise. $N D_{1} \times$ Surprise and $N D_{2} \times$ Surprise are interaction terms. We use a linear model as the baseline model. ${ }^{12}$

We control for actual earnings in the regression, given a significant difference in this variable by call timing shown by the summary statistics. We also expect that the uncertainty of news and the amount of guidance that managers make during calls will impact firms' timing choices. Hence, we control for the uncertainty score throughout managers' speech and the weight of forward-looking information during the presentation sessions. Regarding firm-level controls, we follow Tasker (1998) and Frankel et al. (1999), who discuss the determinants of holding a

\footnotetext{
${ }^{12}$ Instead of explicitly model the asymmetry, we use unsigned value of earnings surprise and the tone of forwardlooking statements in the baseline model.
} 
conference call, and Michaely et al. (2016), who model the timing of earnings announcements. We control for seven firm characteristics we summarize above - firm size, market-to-book ratio, sales growth, number of analysts following, forecast dispersion, financial leverage, and institutional holdings. Firms usually schedule conference calls closely after an earnings release, and earnings release timing likely affects the call timing; hence, we also control for the time slots of the corresponding earnings releases. To control for unobservable omitted variables within year and industry, we include year and industry two-way fixed effects. We cluster standard errors by firm.

H1a argues that firms with bad news strategically time their conference calls after trading hours to trigger less market scrutiny; that is, $\beta_{1}, \beta_{3}, \beta_{4}$ and $\beta_{6}$ should all be negative for both the BMO and AMC groups. Under H1b, firms with more complex backward- and forward-looking news, regardless of the sign of the news, likely hold conference calls after trading hours to give the market more time to digest it and react. $\mathrm{H} 1 \mathrm{~b}$ predicts that $\beta_{1}>0, \beta_{3}<0, \beta_{4}>0$ and $\beta_{6}<0$ because both more positive and more negative news indicates more unexpected information derived from conference calls. Both hypotheses predict that AMC calls will be more influenced by these characters, implying that $\beta_{12}<\beta_{11}<0, \beta_{32}<\beta_{31}<0, \beta_{42}<\beta_{41}<0$, and $\beta_{62}<$ $\beta_{61}<0$ under H1a and that $\beta_{12}>\beta_{11}>0, \beta_{32}<\beta_{31}<0, \beta_{42}>\beta_{41}>0, \beta_{62}<\beta_{61}<0$, and $\beta_{72}>\beta_{71}>0$ under H1b.

We report the regression results in columns (1) to (4) of Table 5. Columns (1) and (2) show the results for the baseline linear model. Firms with higher unsigned earnings surprises and unsigned tone of forward-looking statements are more likely to schedule conference calls outside the regular trading hours, especially after the market closes. Columns (3) and (4) show the results from estimating equation (1). The results strongly support hypothesis $\mathrm{H} 1 \mathrm{~b}$, where $\beta_{1}$ and $\beta_{3}$ are significantly positive, $\beta_{4}$ and $\beta_{6}$ are significantly negative, which together indicate that firms with 
more complex news (both positive and negative) are more likely to schedule conference calls after trading hours. As expected, the magnitudes of the four coefficients are larger for the AMC group than for the BMO group, providing evidence that, when firms have more complex earning news, they are even more likely to schedule an AMC conference call than a BMO call.

In terms of control variables, actual earnings are negatively associated with the likelihood of firms holding a BMO or AMC call. Firms that disclose more forward-looking news during conference calls tend to initiate calls during outside trading hours, especially in the evening. We do not find a significant impact of uncertainty on firms' timing strategies. Consistent with statistics we provide in section 3, we find that larger firms and firms with higher institutional ownership are more likely to hold start earnings calls in the morning before the market opens; firms with higher market-to-book ratio, higher sales growth, and are more likely to hold AMC conference calls.

We address the sticky timing of earnings calls (Table 3 ) by adding the previous call timing as a control variable and re-estimating the same model. The results are shown in columns (5) and (6) of Table 4. We find that the lagged timing choice significantly impacts the current timing choice, reflecting stickiness. While the magnitude of results decreases for both BMO and AMC timing, we find the results for AMC groups more robust. The message of the findings remains the same: firms that deliver more complex backward- and forward-looking information tend to initiate earnings calls outside trading hours, especially in the evenings.

\subsection{Determinants of conference call timing: system equation approach}

Firms often issue a press release to announce the schedule for the forthcoming earnings release and conference calls. Usually, firms release such "notice of earnings" 10 days before the events (Boulland and Dessaint, 2017). Because firms schedule the two events together, a potential endogeneity problem arises. Specifically, the information derived from the news events may only 
impact the timing of the earnings announcements; any finding for the call timings might be more appropriately attributed to release, although the different frequencies in Figure 1 suggest that this is somewhat unlikely.

To alleviate this concern, we use a system of equations to model the two timing choices together. Since few firms announce earnings during regular trading hours, we drop such records and divide the earnings release into those issued before the market opens (BMO) and after the market closes (AMC). We use a logit regression to model the timing of earnings release and consider BMO as a benchmark group. Because the characteristics from conference call transcripts hardly impact firms' timing decisions of the earnings announcements, we only consider earnings surprise as well as other controls and fixed effects as the determinants of earnings release timing. We use the same ordered logit model for the timing of conference calls. We simultaneously estimate the two regressions and state the system of equations formally as follows:

$$
\begin{gathered}
\log \frac{\text { Prob }\left(t_{\_} \text {release }=A M C\right)}{\text { Prob }\left(t_{-} \text {release }=B M O\right)}=\beta_{0}+\beta_{1} \text { Surprise }+\beta_{2} N D_{1}+\beta_{3} N D_{1} \times \text { Surprise }+\Sigma \beta_{k} \text { Controls }_{k}+ \\
F E+\varepsilon \\
\log \frac{\text { Prob }\left(t_{\_} \text {call }=j\right)}{\text { Prob }\left(t_{-} \text {call }=R T H\right)}= \\
\beta_{0}+\beta_{1 j} \text { Surprise }+\beta_{2 j} N D_{1}+\beta_{3 j} N D_{1} \times \text { Surprise }+\beta_{4 j} \text { Tone FLS }+ \\
\beta_{5 j} N D_{2}+\beta_{6 j} N D_{2} \times \text { Tone FLS }+\Sigma \beta_{k j} \text { Controls }_{k}+F E+\varepsilon
\end{gathered}
$$

where $t$ _release is an indicator variable that equals 0 if the firm announces earnings before the market opens and equals 1 if the firm announces earnings after the market closes, and $t \_c a l l$ is defined in the same way as in the multinomial logit model. We estimate the seemingly unrelated equations together by allowing the error terms to be correlated. We use RTH earnings and calls as the reference group for the two equations, respectively, and build a log-odds ratio for BMO and 
AMC events based on the RTH group. Consistent with the previous approach, we include year and industry two-way fixed effects and cluster standard errors by firm.

We report the regression results in Table 6. Column (1) presents the results for the timing of earnings releases and columns (2) and (3) show the results of the timing of conference calls. For the schedule of the earnings releases, $\beta_{1}$ and $\beta_{3}$ are both negative, though marginal for $\beta_{3}$. They together indicate that firms likely schedule earnings release in the evening when they have bad news. The results for the timing of conference calls do not change much from those reported in Table 5 and support $\mathrm{H} 1 \mathrm{~b}: \beta_{1}$ and $\beta_{4}$ are significantly positive, whereas $\beta_{3}$ and $\beta_{6}$ are significantly negative. Moreover, the likelihood of firms scheduling an AMC conference call is higher than scheduling a BMO call only when they have more complex earnings information, rather than forward-looking news. These results suggest that the principles firms use to time earnings announcements and conference calls are different. Firms with more negative news tend to time earnings release in the evenings. In contrast, those with more complex news (both positive and negative) are more likely to initiate conference calls outside trading hours, especially after the market closes.

\subsection{Consequences of conference call timing: market reaction to the timing information}

In this section, we examine how investors react to firms' timing decisions. To analyze whether and how investors understand and respond to the timing information, we perform an event study on the day when firms announce the time of conference calls, which is the first time investors get exposed to the "timing" information. If the market is efficient, investors will infer the news that will derive from the forthcoming conference call when firms schedule the event. By hand collecting data from firms' official websites, we identify the exact date when firms announce the schedule for earnings calls. Since $\mathrm{H} 2 \mathrm{a}$ and $\mathrm{H} 2 \mathrm{~b}$ propose that investors will react to the news 
through market return and trading volume, respectively, we construct a 3-day cumulative abnormal return and trading volume around firms' scheduling date as measures to test the hypotheses. Since firms' timing choices are quite sticky, we expect that the investors will only infer the news in the upcoming disclosure events when there is a timing surprise (i.e., the firm switches the timing). We regress the market reaction on firms' switching behaviors and formally state the model as below: $3-$ day Market Reaction $=\beta_{0}+\beta_{1}$ SwitchRthBmo $+\beta_{2}$ SwitchRthAmc $+\beta_{3}$ SwitchBmoAmc +

$$
\begin{aligned}
& \beta_{4} \text { SwitchBmoRth }+\beta_{5} \text { SwitchAmcBmo }+\beta_{6} \text { SwitchAmcRth }+ \\
& \Sigma \beta_{k j} \text { Controls }_{k}+F E+\varepsilon
\end{aligned}
$$

where Market Reaction is the 3-day cumulative abnormal return (CAR), calculated by the FamaFrench 5-factor model or 3-day trading volume. Our variables of interest are the six indicators of the switching behaviors from RTH to BMO and AMC, from BMO to AMC and RTH, and from AMC to BMO and RTH, denoted in the model as SwitchRthBmo, SwitchRthAmc, SwitchBmoAmc, SwitchBmoRth, SwitchAmcBmo, SwitchAmcRth, respectively. Consistent as in the previous models, we control for the seven firm characteristics - firm size, market-to-book ratio, sales growth, number of analysts following, forecast dispersion, financial leverage, and institutional holdings. To control for unobservable omitted variables, we include year and industry fixed effects, and year and firm fixed effects.

We present the regression results in Table 7. Columns (1) and (2) show the empirical results using 3-day CAR as the measure of market reaction. The investors react negatively to the BMO to RTH switches, though this impact is marginal when we use a firm fixed effect. The interpretation of the results is not straight forward since neither of $\mathrm{H} 2 \mathrm{a}$ nor $\mathrm{H} 2 \mathrm{~b}$ predicts such market response. Columns (3) and (4) present the results for the trading volume. We find positive coefficients for the switches from RTH to BMO and AMC, indicating that investors infer more extreme (either 
good or bad) news when firms announce a call timing switch from regular hours. These results provide some support for $\mathrm{H} 2 \mathrm{~b}$ by documenting a more volatile market reaction when investors get notified of a switch from regular trading hours to outside trading hours.

$\mathrm{H} 3$ predicts that the association in $\mathrm{H} 2$ will be more significant when firms have multiple switches during the sample period, and when the "scheduling" events are close to conference calls. To test this hypothesis, we first use a subsample of firms that switch the call timing at least three times. We expect that these firms likely schedule the conference calls strategically; investors will better understand the strategy of such firms and react to their "timing" information more efficiently. We present the results in columns (5) and (6). We do find consistent but slightly stronger results for the subsample that trading volume is significantly higher when firms switch the call timing from regular trading hours to outside trading hours. Moreover, the trading volume is also higher, though marginal, when firms announce a switch from morning to evening.

We further run a subsample test using the firm-quarter observations from the firms that announce the schedule of the earnings calls relatively close to the calls themselves. When the scheduling date is close to the event date, managers as insiders, likely get a sense of the earnings news and make guidance based on the current performance. Hence, they may use the information to carefully time the events. Moreover, investors will get more proactive and infer the news that will derive from conference calls from the "timing" when it is close to the events. Boulland and Dessaint (2017) document that firms release a notice of earnings 10 days before the news events. We find an average of 16.5 days and a median of 14 days between the scheduling date and the event date. We only keep those records from the firms that issue the "scheduling" press release within 14 days before the earnings announcements. To remove the impact of the news events, we also remove those records from the firms that announce the schedule within 2 days before the 
earnings release. We present the results in columns (7) and (8). Compared with the regressions using the full sample, we do find more significant coefficients for the switching indicators when firms announce the schedule close to the events.

\subsection{Additional discussion: hiding or helping?}

In the previous analysis, we provide support for $\mathrm{H} 1 \mathrm{~b}, \mathrm{H} 2 \mathrm{~b}$, and $\mathrm{H} 3$, which together indicate that firms give the market more time to digest and interpret complex information. On the determinants side, firms are more likely to start conference calls outside trading hours when they have larger earnings surprise to discuss or when they have more positive or negative forwardlooking news to distribute. On the consequence side, the trading volume significantly increases when the market is aware of a switch of call timing from trading hour to outside trading hour, suggesting that investors infer the more extreme news during the upcoming event. However, we cannot entirely reject the "hiding" hypotheses. Specifically, when firms have negative news to disclose, both hiding and helping stories could explain the results.

We further detangle the two possibilities by analyzing the correlation between backwardand forward-looking news. Because earnings surprise is determined by firms' performance in the previous quarter and analysts' consensus forecast, managers have limited discretion on how to discuss them during conference calls. However, they may disclose the future-oriented conversation more strategically. If firms aim to avoid public scrutiny on the negative earnings news, they may increase the number of forward-looking statements they communicate during calls to distract investors from the earnings information. Moreover, managers may also discretionarily reveal an optimistic outlook to offset the negative impact of the earnings surprise. Therefore, if managers strategically time the events to hide bad news, we expect a positive correlation between earnings 
surprise and weight of forward-looking statements and a negative correlation between earnings news and forward-looking information when firms have negative earnings surprises.

Empirically, we partition our sample into those with negative and positive earnings surprise and examine the relationship between backward- and forward-looking news. We present the results in Table 8. We find a negative correlation between earnings surprise and tone of forward-looking statements only for the subsample with positive earnings news (Panel A). However, when earnings news is negative, the correlation between the two variables is significantly positive (Panel B). If we analyze managers' tone throughout the presentation session rather than that of forward-looking statements only, the results remain the same. Still contrary to the expectation from "hiding" hypotheses, we find the correlation negative between the weight of forward-looking statements and earnings surprise when firms do not meet analysts' consensus. The results altogether suggest that managers communicate more conservatively when they disclose bad news and that hiding is unlikely.

\section{Conclusion}

Because of their forward-looking statements and interactive nature, earnings conference calls are such informative disclosure events that managers carefully schedule them. We examine why firms time conference calls differently and how the stock market interprets and reacts to firms' timing choices. By collecting call timings from Bloomberg, we first comprehensively examine the intra-day time distribution of conference calls. We show that compared with the timing of earnings release, which is pervasively studied by prior literature, the timing of conference calls is more dispersed across the day. Moreover, we find that conference calls provide considerable timing variation in cross-section and that most firms in our sample switch the call timings at least once. 
Hence, we believe conference calls as an ideal setting to explore firms' strategic timing due to their importance and data variation.

We find that firms with more complex news (good or bad) are more likely to schedule conference calls after the market closes, especially in the evening. We examine news derived from conference calls using earnings surprise (backward-looking) and the tone of forward-looking statements during the presentation sessions of calls. We find both information sources impact firms' timing decisions. The sticky timing choice and that the simultaneous scheduling of earnings announcements and conference calls introduce empirical challenges. We address these concerns and find consistent results by controlling the lagged timing choice and by employing system-ofequations regression to model the two timing choices together. To examine how investors interpret and react to firms' timing choices, we conduct an event study around the date when firms announce the schedule. We provide evidence that investors infer the upcoming news characteristics from the firms switching behaviors.

The results altogether suggest that firms help investors to better understand the complex news and schedule conference calls outside trading hours. We further reinforce this interpretation by analyzing the correlation of backward- and forward-looking information when earnings surprise is negative. If firms adopt a "hiding" mechanism to schedule calls, they likely deliberately disclose optimistic guidance, or at least communicate the forward-looking statements in a more positive tone, to reconcile the negative impact of "bad" earnings. However, we find that managers speak in a more conservative manner when they have negative earnings news. Overall, our findings help understand how firms time their calls and how investors understand firms' timing choices. As a rising venue of corporate disclosure, we find that firms strategically time conference calls to help the market digest complex information. 


\section{Reference}

Benninga, Simon, Mark Helmantel, and Oded Sarig. "The timing of initial public offerings." Journal of Financial Economics 75.1 (2005): 115-132.

Boulland, Romain, and Olivier Dessaint. "Announcing the announcement." Journal of Banking \& Finance 82 (2017): 59-79.

Bozanic, Zahn, Darren T. Roulstone, and Andrew Van Buskirk. "Management earnings forecasts and other forward-looking statements." Journal of Accounting and Economics 65.1 (2018): 120.

Bradley, Daniel, Jonathan Clarke, Suzanne Lee, and Chayawat Ornthalanai. "Are analysts' recommendations informative? Intraday evidence on the impact of time stamp delays." The Journal of Finance 69.2 (2014): 645-673.

Brochet, Francois, Kalin Kolev, and Alina Lerman. "Information transfer and conference calls." Review of Accounting Studies 23.3 (2018): 907-957.

Brockman, Paul, and Dennis Y. Chung. "Managerial timing and corporate liquidity: evidence from actual share repurchases." Journal of Financial Economics 61.3 (2001): 417-448.

Brogaard, Jonathan, Terrence Hendershott, and Ryan Riordan. "High-frequency trading and price discovery." The Review of Financial Studies 27.8 (2014): 2267-2306.

Bowen, Robert M., Angela K. Davis, and Dawn A. Matsumoto. "Do conference calls affect analysts' forecasts?" The Accounting Review 77.2 (2002): 285-316.

Bushee, Brian J., Dawn A. Matsumoto, and Gregory S. Miller. "Open versus closed conference calls: the determinants and effects of broadening access to disclosure." Journal of Accounting and Economics 34.1-3 (2003): 149-180.

Bushee, Brian J., Dawn A. Matsumoto, and Gregory S. Miller. "Managerial and investor responses to disclosure regulation: The case of Reg FD and conference calls." The Accounting Review 79.3 (2004): 617-643.

Call, Andrew C., Nathan Y. Sharp, and Thomas Shohfi. "Implications of buy-side analysts' participation in public earnings conference calls. " Working paper, 2017.

Chen, Jing, Elizabeth Demers, and Baruch Lev. "Oh what a beautiful morning! Diurnal influences on executives and analysts: Evidence from conference calls." Management Science 64.12 (2018): 5899-5924.

Davis, Angela K., Weili Ge, Dawn A. Matsumoto, and Jenny L. Zhang. "The effect of managerspecific optimism on the tone of earnings conference calls." Review of Accounting Studies 20.2 (2015): 639-673.

DeHaan, Ed, Terry J. Shevlin, and Jacob R. Thornock. "Market (in) attention and the strategic scheduling and timing of earnings announcements." Journal of Accounting and Economics 60.1 (2015): 36-55. 
DellaVigna, Stefano, and Joshua M. Pollet. "Investor inattention and Friday earnings announcements." The Journal of Finance 64.2 (2009): 709-749.

Doyle, Jeffrey T., and Matthew J. Magilke. "The timing of earnings announcements: An examination of the strategic disclosure hypothesis." The Accounting Review 84.1 (2009): 157182.

Fama, Eugene F., and Kenneth R. French. "A five-factor asset pricing model." Journal of Financial Economics 116.1 (2015): 1-22.

Francis, Jennifer, Donald Pagach, and Jens Stephan. "The stock market response to earnings announcements released during trading versus nontrading periods." Journal of Accounting Research 30.2 (1992): 165-184.

Frankel, Richard, Marilyn Johnson, and Douglas J. Skinner. "An empirical examination of conference calls as a voluntary disclosure medium." Journal of Accounting Research 37.1 (1999): 133-150.

Gennotte, Gerard, and Brett Trueman. "The strategic timing of corporate disclosures." The Review of Financial Studies 9.2 (1996): 665-690.

Gow, Ian D., David F. Larcker, and Anastasia A. Zakolyukina. "Non-answers during conference calls." Chicago Booth Research Paper 19-01 (2019).

Guttman, Ilan, Ohad Kadan, and Eugene Kandel. "Dividend stickiness and strategic pooling." The Review of Financial Studies 23.12 (2010): 4455-4495.

Healy, Paul M., and Krishna G. Palepu. "Earnings information conveyed by dividend initiations and omissions." Journal of Financial Economics 21.2 (1988): 149-175.

Heinrichs, Anne, Jihwon Park, and Eugene F. Soltes. "Who consumes firm disclosures? Evidence from earnings conference calls." The Accounting Review 94.3 (2019): 205-231.

Hirshleifer, David, Sonya Seongyeon Lim, and Siew Hong Teoh. "Driven to distraction: Extraneous events and underreaction to earnings news." The Journal of Finance 64.5 (2009): 2289-2325.

Hollander, Stephan, Maarten Pronk, and Erik Roelofsen. "Does silence speak? An empirical analysis of disclosure choices during conference calls." Journal of Accounting Research 48.3 (2010): 531-563.

Jenter, Dirk. "Market timing and managerial portfolio decisions." The Journal of Finance 60.4 (2005): 1903-1949.

Jiang, Christine X., Tanakorn Likitapiwat, and Thomas H. McInish. "Information content of earnings announcements: Evidence from after-hours trading." Journal of Financial and Quantitative Analysis 47.6 (2012): 1303-1330.

Jung, Michael J., M.H. Franco Wong, and X. Frank Zhang. "Buy-side analysts and earnings conference calls." Journal of Accounting Research 56.3 (2018): 913-952.

Kimbrough, Michael D. "The effect of conference calls on analyst and market underreaction to earnings announcements." The Accounting Review 80.1 (2005): 189-219. 
Koch, Adam S., and Amy X. Sun. "Dividend changes and the persistence of past earnings changes." The Journal of Finance 59.5 (2004): 2093-2116.

Lansford, Benjamin, Jimmy Lee, and Jennifer W. Tucker. "Disclosure of management guidance in conference calls: Materiality, determinants and consequences." http://ssrn.com/abstract=1270974.

Larcker, David F., and Anastasia A. Zakolyukina. "Detecting deceptive discussions in conference calls." Journal of Accounting Research 50.2 (2012): 495-540.

Li, Feng, et al. "Knowledge, compensation, and firm value: An empirical analysis of firm communication." Journal of Accounting and Economics 58.1 (2014): 96-116.

Livnat, Joshua, and Richard R. Mendenhall. "Comparing the post-earnings announcement drift for surprises calculated from analyst and time series forecasts." Journal of Accounting Research 44.1 (2006): 177-205.

Malkiel, Burton G. "The efficient market hypothesis and its critics." Journal of Economic Perspectives 17.1 (2003): 59-82.

Matsumoto, Dawn, Maarten Pronk, and Erik Roelofsen. "What makes conference calls useful? The information content of managers' presentations and analysts' discussion sessions." The Accounting Review 86.4 (2011): 1383-1414.

Mayew, William J., Nathan Y. Sharp, and Mohan Venkatachalam. "Using earnings conference calls to identify analysts with superior private information." Review of Accounting Studies 18.2 (2013): 386-413.

Michaely, Roni, Amir Rubin, and Alexander Vedrashko. "Further evidence on the strategic timing of earnings news: Joint analysis of weekdays and times of day." Journal of Accounting and Economics 62.1 (2016): 24-45.

Patell, James M., and Mark A. Wolfson. "Good news, bad news, and the intraday timing of corporate disclosures." The Accounting Review 57.3 (1982): 509-527.

Price, S. McKay, et al. "Earnings conference calls and stock returns: The incremental informativeness of textual tone." Journal of Banking \& Finance 36.4 (2012): 992-1011.

Schoenecker, Timothy S., and Arnold C. Cooper. "The role of firm resources and organizational attributes in determining entry timing: a cross-industry study." Strategic Management Journal 19.12 (1998): 1127-1143.

Stenbacka, Rune, and Mihkel M. Tombak. "Strategic timing of adoption of new technologies under uncertainty." International Journal of Industrial Organization 12.3 (1994): 387-411.

Tasker, Sarah C. "Bridging the information gap: Quarterly conference calls as a medium for voluntary disclosure." Review of Accounting Studies 3.1-2 (1998): 137-167. 


\section{Appendix A: Forward-looking words to identify forward-looking statements}

\begin{tabular}{|c|c|c|}
\hline also aim & and intend & but commits \\
\hline also aims & and intends & but estimate \\
\hline also anticipate & and plan & but estimates \\
\hline also anticipates & and plans & but expect \\
\hline also assume & and project & but expects \\
\hline also assumes & and projects & but forecast \\
\hline also believe & and seek & but forecasts \\
\hline also believes & and seeks & but foresee \\
\hline also commit & and target & but foresees \\
\hline also commits & and targets & but hope \\
\hline also estimate & and will & but hopes \\
\hline also estimates & are aimed & but intend \\
\hline also expect & are aiming & but intends \\
\hline also expects & are anticipated & but plan \\
\hline also forecast & are anticipating & but plans \\
\hline also forecasts & are assumed & but project \\
\hline also foresee & are assuming & but projects \\
\hline also foresees & are believed & but seek \\
\hline also hope & are believing & but seeks \\
\hline also hopes & are committed & but target \\
\hline also intend & are committing & but targets \\
\hline also intends & are estimated & coming fiscal \\
\hline also plan & are estimating & coming month \\
\hline also plans & are expected & coming period \\
\hline also project & are expecting & coming quarter \\
\hline also projects & are forecasted & coming year \\
\hline also seek & are forecasting & company aims \\
\hline also seeks & are foreseeing & company \\
\hline also target & are foreseen & company assumes \\
\hline also targets & are hoped & company believes \\
\hline and aim & are intending & company commits \\
\hline and aims & are planed & company estimates \\
\hline and anticipate & are planning & company expects \\
\hline and anticipates & are projected & company forecasts \\
\hline and assume & are projecting & company foresees \\
\hline and believes & are seeking & company hopes \\
\hline and commit & are sought & company intends \\
\hline and commits & are targeted & company plans \\
\hline and estimate & are targeting & company projects \\
\hline and estimates & but aim & company seeks \\
\hline and expect & but aims & company targets \\
\hline and expects & but anticipate & corporation aims \\
\hline and forecast & but anticipates & corporation \\
\hline and forecasts & but assume & corporation \\
\hline and foresee & but assumes & corporation \\
\hline and foresees & but believe & corporation \\
\hline nd hope & but believes & corporation \\
\hline nd hopes & but commit & corporation expects \\
\hline
\end{tabular}

corporation
corporation
corporation hopes
corporation intends
corporation plans
corporation projects
corporation seeks
corporation targets
currently aim
currently aimed
currently aiming
currently aims
currently anticipate
currently
currently
currently
currently assume
currently assuming
currently believe
currently believed
currently believes
currently believing
currently commit
currently commits
currently
currently
currently estimate
currently estimated
currently estimates
currently estimating
currently expect
currently expected
currently expecting
currently expects
currently forecast
currently forecasted
currently
currently forecasts
currently foresee
currently foreseeing
currently foreseen
currently foresees
currently hope
currently hoped
currently hopes
currently hoping




\begin{tabular}{|c|c|c|c|}
\hline currently intending & firm aims & is projecting & normally projects \\
\hline currently intends & firm anticipates & is seeking & normally seek \\
\hline currently plan & firm assumes & is sought & normally seeks \\
\hline currently planed & firm believes & is targeted & normally target \\
\hline currently planning & firm commits & is targeting & normally targets \\
\hline arrently plans & firm estimates & management aims & not aimed \\
\hline urrently project & firm expects & management & not aiming \\
\hline currently projected & firm forecasts & management & not anticipated \\
\hline arrently projecting & firm foresees & management & not anticipating \\
\hline arrently projects & firm hopes & management & not assumed \\
\hline irrently seek & firm intends & management & not assuming \\
\hline Irrently seeking & firm plans & management & not believed \\
\hline irrently seeks & firm projects & management & not believing \\
\hline urrently sought & firm seeks & management & not committed \\
\hline urrently target & firm targets & management hopes & not committing \\
\hline arrently targeted & following fiscal & management & not estimating \\
\hline urrently targeting & following month & management plans & not expected \\
\hline urrently targets & following period & management & not expecting \\
\hline urrently will & following quarter & management seeks & not estimated \\
\hline urrently willing & following year & management targets & not forecasted \\
\hline not aim & incoming fiscal & next fiscal & not forecasting \\
\hline not anticipate & incoming month & next month & not foreseeing \\
\hline o not assume & incoming period & next period & not foreseen \\
\hline not believe & incoming quarter & next quarter & not hoped \\
\hline not commit & incoming year & next year & not hoping \\
\hline not estimate & is aimed & normally aim & not intended \\
\hline not expect & is aiming & normally aims & not intending \\
\hline not forecast & is anticipated & normally anticipate & not planed \\
\hline not foresee & is anticipating & normally & not planning \\
\hline not hope & is assumed & normally assume & not projected \\
\hline not intend & is assuming & normally assumes & not projecting \\
\hline not plan & is believed & normally believe & not seeking \\
\hline not project & is believing & normally believes & not sought \\
\hline not seek & is committed & normally commit & not targeted \\
\hline not target & is committing & normally commits & not targeting \\
\hline es not aim & is estimated & normally estimate & now aim \\
\hline es not anticipate & is estimating & normally estimates & now aimed \\
\hline es not assume & is expected & normally expect & now aiming \\
\hline ees not believe & is expecting & normally expects & now aims \\
\hline es not commit & is forecasted & normally forecast & now anticipate \\
\hline es not estimate & is forecasting & normally forecasts & now anticipated \\
\hline es not expect & is foreseeing & normally foresee & now anticipates \\
\hline es not forecast & is foreseen & normally foresees & now anticipating \\
\hline es not foresee & is hoped & normally hope & now assume \\
\hline es not hope & is hoping & normally hopes & now assumed \\
\hline es not intend & is intended & normally intend & now assumes \\
\hline es not plan & is intending & normally intends & now assuming \\
\hline es not project & is planed & normally plan & now believe \\
\hline not seek & is planning & normally plans & now believed \\
\hline tes not target & is projected & normally project & now believes \\
\hline
\end{tabular}




\begin{tabular}{|c|c|c|}
\hline now believing & still anticipated & still sought \\
\hline now commit & still anticipates & still target \\
\hline now targeted & still anticipating & still targeted \\
\hline now targeting & still assume & still targeting \\
\hline now targets & still assumed & still targets \\
\hline now commits & still assumes & subsequent fiscal \\
\hline now committed & still assuming & subsequent month \\
\hline now committing & still believe & subsequent period \\
\hline now estimate & still believed & subsequent quarter \\
\hline now estimated & still believes & subsequent year \\
\hline now estimates & still believing & upcoming fiscal \\
\hline now estimating & still commit & upcoming month \\
\hline now expect & still commits & upcoming period \\
\hline now expected & still committed & upcoming quarter \\
\hline now expecting & still committing & upcoming year \\
\hline now expects & still estimate & we aim \\
\hline now forecast & still estimated & we anticipate \\
\hline now forecasted & still estimates & we assume \\
\hline now forecasting & still estimating & we believe \\
\hline now forecasts & still expect & we commit \\
\hline now foresee & still expected & we estimate \\
\hline now foreseeing & still expecting & we expect \\
\hline now foreseen & still expects & we forecast \\
\hline now foresees & still forecast & we foresee \\
\hline now hope & still forecasted & we hope \\
\hline now hoped & still forecasting & we intend \\
\hline now hopes & still forecasts & we plan \\
\hline now hoping & still foresee & we project \\
\hline now intend & still foreseeing & we seek \\
\hline now intended & still foreseen & we target \\
\hline now intending & still foresees & we will \\
\hline now intends & still hoping & \\
\hline now plan & still hope & \\
\hline now planed & still hoped & \\
\hline now planning & still hopes & \\
\hline now plans & still intend & \\
\hline now project & still intended & \\
\hline now projected & still intending & \\
\hline now projecting & still intends & \\
\hline now projects & still plan & \\
\hline now seek & still planed & \\
\hline now seeking & still planning & \\
\hline now seeks & still plans & \\
\hline now sought & still project & \\
\hline now target & still projected & \\
\hline still aim & still projecting & \\
\hline still aimed & still projects & \\
\hline still aiming & still seek & \\
\hline still aims & still seeking & \\
\hline still anticipate & still seeks & \\
\hline
\end{tabular}


Appendix B: Variable definitions

\begin{tabular}{|c|c|}
\hline Variable & Definition \\
\hline \multicolumn{2}{|l|}{ Timing choices } \\
\hline t_call & $\begin{array}{l}\text { An indicator variable that equals } 0 \text { if the firm holds the conference call } \\
\text { during the regular trading hour, } 1 \text { if the firm holds the conference call in } \\
\text { the morning before the market opens, and } 2 \text { if the firm holds the } \\
\text { conference call in the evening after the market closes. }\end{array}$ \\
\hline t_release & $\begin{array}{l}\text { An indicator variable that equals } 0 \text { if the firm announces earnings during } \\
\text { the regular trading hour, } 1 \text { if the firm announces earnings in the morning } \\
\text { before the market opens, and } 2 \text { if the firm announces earnings in the } \\
\text { evening after the market closes. }\end{array}$ \\
\hline Lagged_call & The lagged term of $t_{-}$call. \\
\hline Lagged_ann & The lagged term of $t$ release. \\
\hline \multicolumn{2}{|l|}{ Market response } \\
\hline $\mid$ Volume $(-1,+1) \mid$ & $\begin{array}{l}\text { The natural log of 3-day abnormal trading volume around the date when } \\
\text { the firm announces conference call schedule. }\end{array}$ \\
\hline$|C A R(-1,+1)|$ & $\begin{array}{l}\text { The 3-day cumulative value-weighted abnormal return, computed by the } \\
\text { Fama-French } 5 \text {-factor model, around the date when the firm announces } \\
\text { the conference call schedule. }\end{array}$ \\
\hline \multicolumn{2}{|c|}{ Information derived from conference calls } \\
\hline Earnings Surprise & $\begin{array}{l}\text { The difference between actual announced earnings per share and the } \\
\text { median of analyst forecasts, scaled by the beginning-of-period stock } \\
\text { price. }\end{array}$ \\
\hline |Earnings Surprise $\mid$ & The absolute value of Earnings Surprise. \\
\hline Tone FLS & $\begin{array}{l}\text { The mean of the tone of forward-looking statements during the } \\
\text { presentation session a conference call. }\end{array}$ \\
\hline $\mid$ Tone FLS| & The absolute value of Tone FLS. \\
\hline ND1 & $\begin{array}{l}\text { An indicator variable that equals } 1 \text { if the firm has negative earnings } \\
\text { surprise, and } 0 \text { otherwise. }\end{array}$ \\
\hline ND1 X Surprise & The interaction between NDI and Earnings Surprise. \\
\hline$N D 2$ & $\begin{array}{l}\text { An indicator variable that equals } 1 \text { if the firm has negative tone of } \\
\text { forward-looking statements, and } 0 \text { otherwise. }\end{array}$ \\
\hline ND2 X Tone FLS & The interaction between $N D 2$ and Tone FLS. \\
\hline \multicolumn{2}{|c|}{ Other characteristics of conference calls } \\
\hline Uncertainty & $\begin{array}{l}\text { The average uncertainty score, computed by Loughran-McDonald } \\
\text { dictionary, throughout the presentation session of conference call. }\end{array}$ \\
\hline
\end{tabular}




\begin{tabular}{|c|c|}
\hline Tone PrS & $\begin{array}{l}\text { The mean of the tone over the sentences throughout the presentation } \\
\text { session of a conference call. }\end{array}$ \\
\hline FLS Focus & $\begin{array}{l}\text { The number of forward-looking statements over the total number of } \\
\text { sentences throughout the presentation session of a conference call. }\end{array}$ \\
\hline Len_call & The natural log of the number of words throughout a conference call. \\
\hline Len_PrS & $\begin{array}{l}\text { The natural log of the number of words throughout the presentation } \\
\text { session of a conference call. }\end{array}$ \\
\hline AQ Ratio & $\begin{array}{l}\text { The number of words managers speak to answer questions over the } \\
\text { number of words analysts speak to ask questions. }\end{array}$ \\
\hline \# anal part & The number of analysts that participate a conference call. \\
\hline \# firm part & $\begin{array}{l}\text { The number of firm executives that participate and speak during a } \\
\text { conference call. }\end{array}$ \\
\hline \multicolumn{2}{|c|}{ Switching behaviors } \\
\hline SwitchRthBmo & $\begin{array}{l}\text { An indicator variable that equals } 1 \text { if the firm holds a conference call } \\
\text { before the market opens in the current quarter, but held a call during } \\
\text { regular trading hours in the previous period; and } 0 \text { otherwise. }\end{array}$ \\
\hline SwitchRthAmc & $\begin{array}{l}\text { An indicator variable that equals } 1 \text { if the firm holds a conference call } \\
\text { after the market closes in the current quarter, but held a call during } \\
\text { regular trading hours in the previous period; and } 0 \text { otherwise. }\end{array}$ \\
\hline SwitchBmoRth & $\begin{array}{l}\text { An indicator variable that equals } 1 \text { if the firm holds a conference call } \\
\text { during regular trading hours in the current quarter, but held a call before } \\
\text { the market opens in the previous period; and } 0 \text { otherwise. }\end{array}$ \\
\hline SwitchBmoAmc & $\begin{array}{l}\text { An indicator variable that equals } 1 \text { if the firm holds a conference call } \\
\text { after the market closes in the current quarter, but held a call before the } \\
\text { market opens in the previous period; and } 0 \text { otherwise. }\end{array}$ \\
\hline SwitchAmcBmo & $\begin{array}{l}\text { An indicator variable that equals } 1 \text { if the firm holds a conference call } \\
\text { before the market opens in the current quarter, but held a call after the } \\
\text { market closes in the previous period; and } 0 \text { otherwise. }\end{array}$ \\
\hline SwitchAmcRth & $\begin{array}{l}\text { An indicator variable that equals } 1 \text { if the firm holds a conference call } \\
\text { during regular trading hours in the current quarter, but held a call after } \\
\text { the market closes in the previous period; and } 0 \text { otherwise. }\end{array}$ \\
\hline \multicolumn{2}{|c|}{ Firm characteristics } \\
\hline Actual & The actual earnings per share. \\
\hline Size & The natural log of total assets. \\
\hline Mtb Ratio & The ratio of the market value to the book value of firms' assets. \\
\hline Leverage & Total liabilities divided by total assets. \\
\hline
\end{tabular}




\begin{tabular}{|l|l|}
\hline Analyst & The natural log of number of analysts following. \\
\hline Dispersion & The standard deviation of analyst forecasts. \\
\hline Sales Growth & Sales growth adjusted by seasonality. \\
\hline Inst. Ownership & The percentage of firms' shares by institutional investors. \\
\hline
\end{tabular}


Figure 1. Timing trend of the earnings release and conference calls during 2008-2017

Panel A. Timing trend of earnings release during $2008-2017$

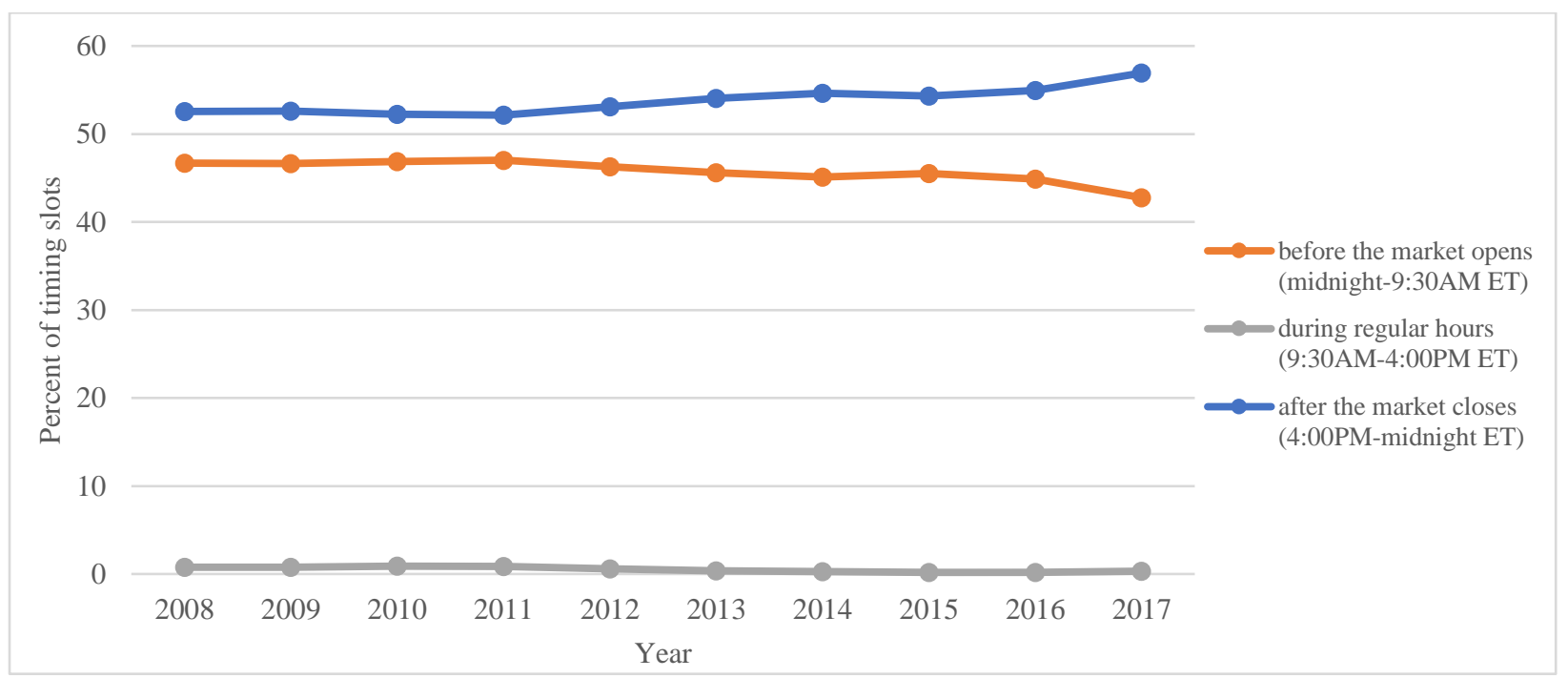

Panel B. Timing trend of earnings conference calls during 2008 - 2017

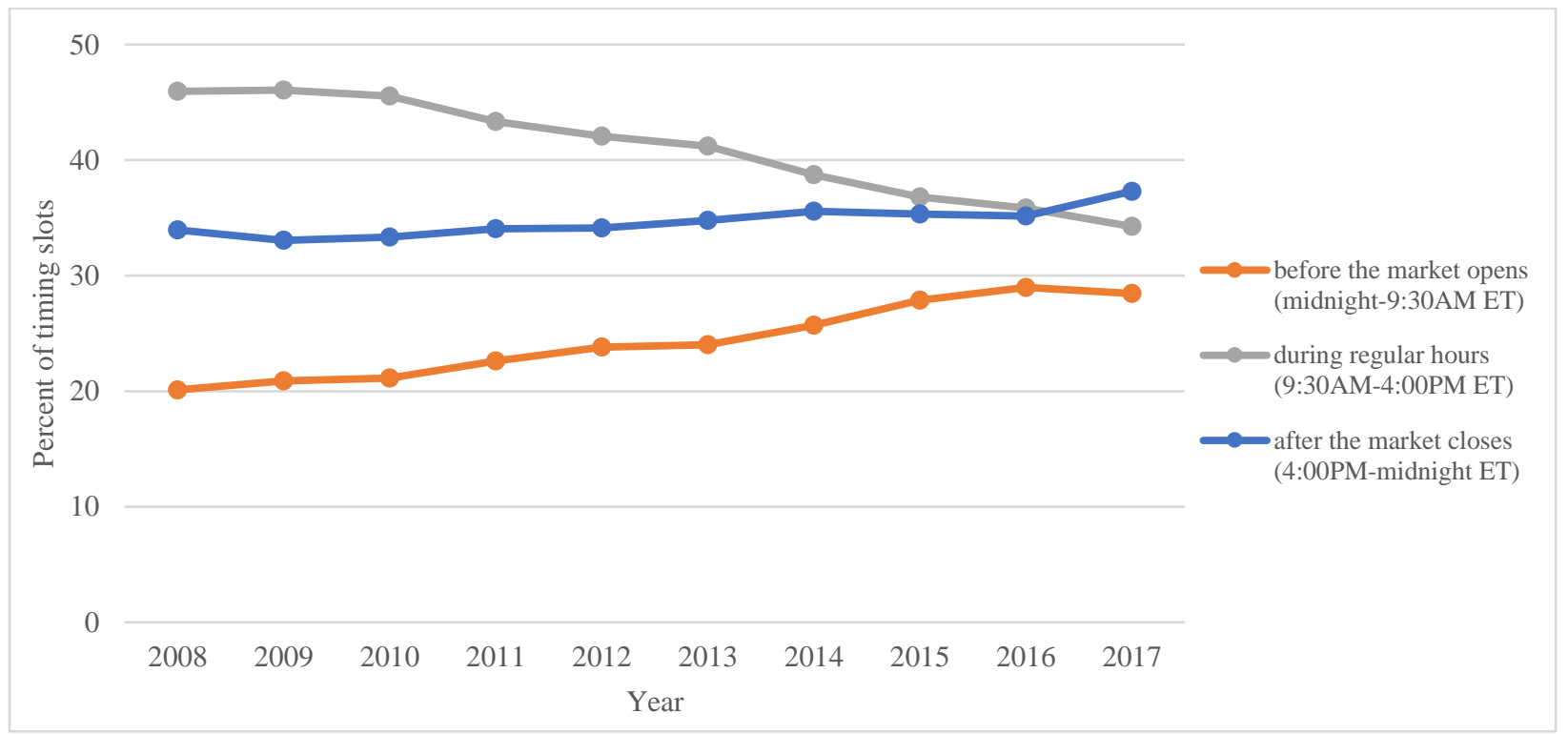


Figure 2. Earnings announcements and Earnings conference calls by time of day

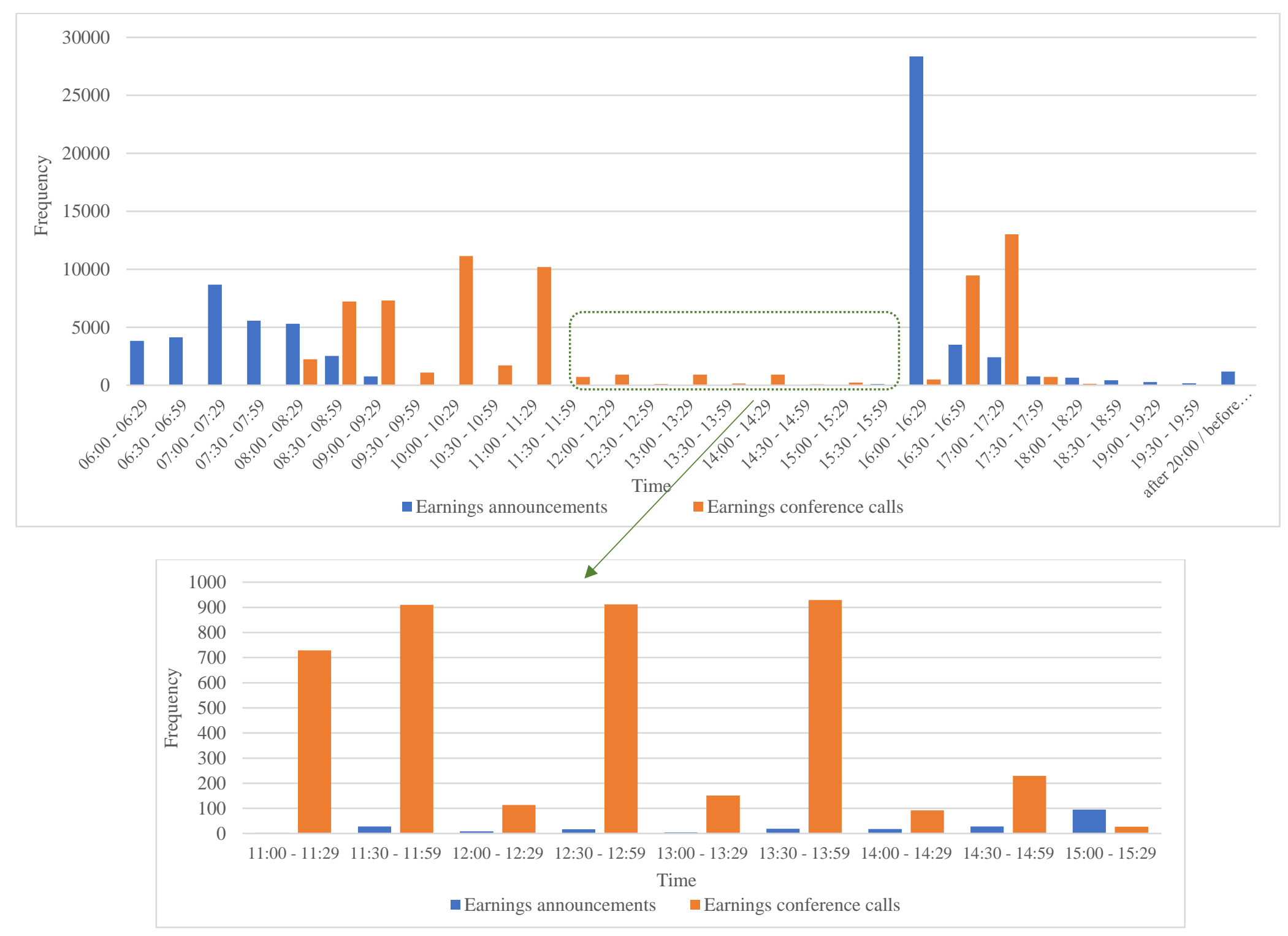


Figure 3. Frequency of timing switches during 2008 - 2017

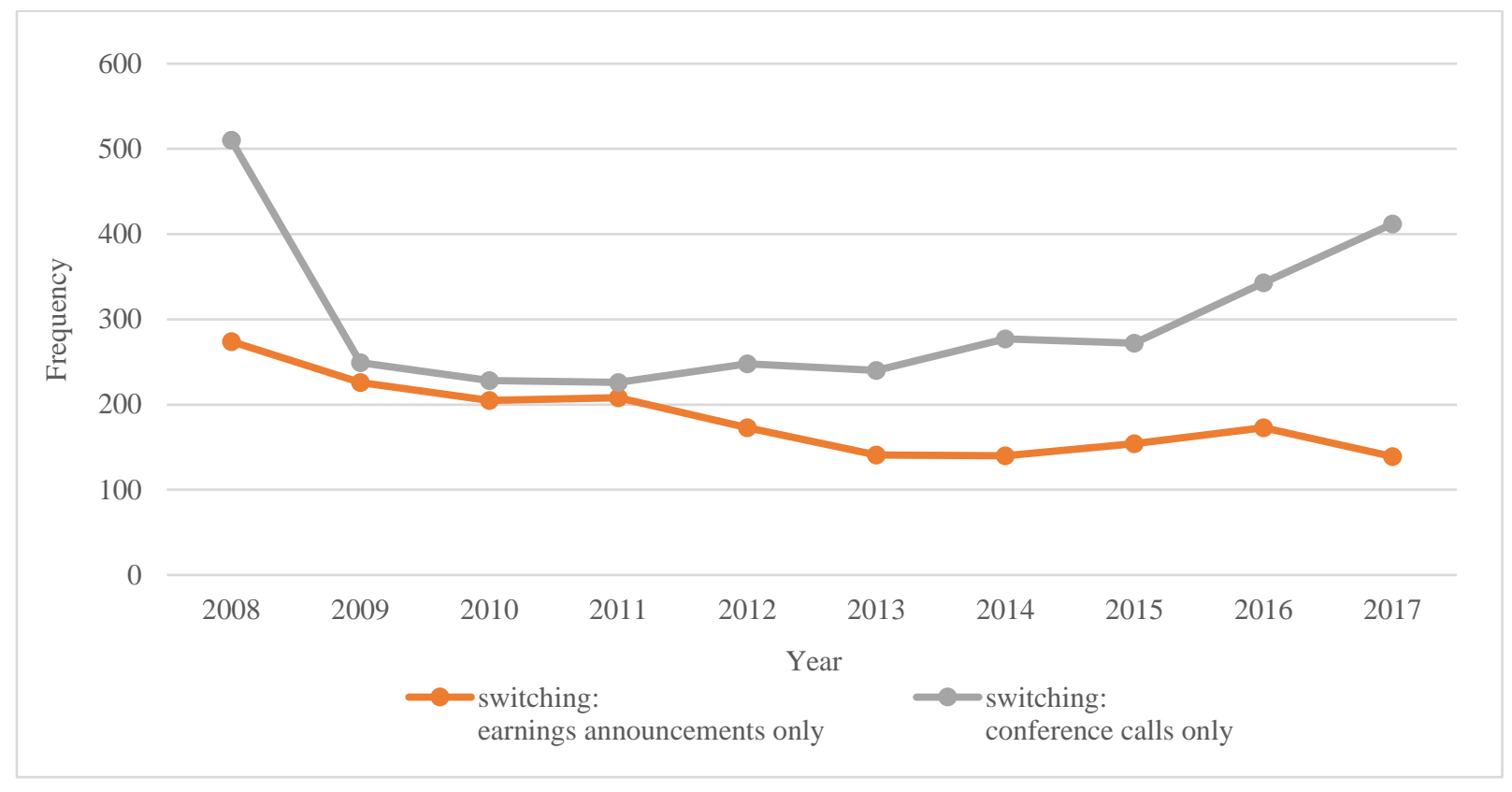




\section{Table 1: Time Data Validation from Bloomberg and sample selection}

Panel A: validation of timing data for conference calls from Bloomberg

Bloomberg records for conference calls with complete timing information from 2008 to 2017

Bloomberg records which can be credibly linked to an identifier (ticker/cik/gvkey/permno)

Bloomberg records with the date of call identifiable through firms' press release and media coverage

Less: Bloomberg date of calls that cannot be verified by any of the other sources

Bloomberg records with verifiable dates

Ratio of verifiable date-level Bloomberg records

Bloomberg records with the time (minute level) of call identifiable through firms' press release and media coverage

Less: Bloomberg time of call cannot be verified by any of the other sources

Bloomberg records with verifiable time

Ratio of verifiable minute-level Bloomberg records

Panel B: comparison of the accuracy of announcement timing from Bloomberg and $I / B / E / S$

Earnings announcements being identified from both Bloomberg and I/B/E/S from 2008 to 2017

Less: Records with consistent date and time information from Bloomberg and I/B/E/S

Information from Bloomberg and $\mathrm{I} / \mathrm{B} / \mathrm{E} / \mathrm{S}$ is inconsistent

Inconsistent information

Number of inconsistent observations

Number of observations we verify

Number of correct observations from Bloomberg 


\section{Panel C: sample selection procedure}

Bloomberg records for both earnings announcements and conference calls with complete timing information from 2008 to 2017

Less: those

from financial industry

with insufficient earnings characteristics from I/B/E/S

with no identifiable conference call transcripts

with insufficient financial information from CompuStat

with insufficient institutional ownership information from Thomson Reuters

with stock price lower than $\$ 1$

Sample of paired events (earnings release and conference call) for statistics

Less: those from firms that never switch the timing of conference calls

$68,981 \quad 3,295$

Sample of paired events for $\mathrm{H} 1$

Less: those without identifiable "scheduling" press release 
Table 2: Timing pattern of earnings announcements and conference calls

\begin{tabular}{|c|c|c|c|c|c|c|c|c|c|c|c|c|c|c|c|c|c|}
\hline \multirow{2}{*}{\multicolumn{2}{|c|}{ announcem }} & \multicolumn{3}{|c|}{ Monday } & \multicolumn{3}{|c|}{ Tuesday } & \multicolumn{3}{|c|}{ Wednesday } & \multicolumn{3}{|c|}{ Thursday } & \multicolumn{3}{|c|}{ Friday } & \multirow{2}{*}{$\begin{array}{c}\text { Total percent of } \\
\text { the announcement } \\
\text { on weekdays }\end{array}$} \\
\hline & & $\mathrm{BMO}$ & RTH & AMC & $\mathrm{BMO}$ & RTH & $\mathrm{AMC}$ & $\mathrm{BMO}$ & RTH & $\mathrm{AMC}$ & $\mathrm{BMO}$ & RTH & $\mathrm{AMC}$ & $\mathrm{BMO}$ & RTH & AMC & \\
\hline \multirow{3}{*}{ Monday } & BMO & 862 & 1350 & 39 & 4 & 23 & 1 & & 5 & & & & & & & & \multirow{3}{*}{11.58} \\
\hline & RTH & & 21 & 15 & 1 & 19 & 1 & & & & & & & & & & \\
\hline & $\mathrm{AMC}$ & & & 2944 & 1066 & 1598 & 21 & 11 & 8 & 2 & & & & & & & \\
\hline \multirow{3}{*}{ Tuesday } & BMO & & & & 2630 & 4255 & 70 & 6 & 28 & 2 & 4 & 3 & 1 & & & & \multirow{3}{*}{22.69} \\
\hline & RTH & & & & & 34 & 39 & 1 & 5 & 0 & 0 & 1 & & & & & \\
\hline & $\mathrm{AMC}$ & & & & & & 5585 & 1250 & 1709 & 14 & 5 & 13 & & & & & \\
\hline \multirow{3}{*}{ Wednesday } & $\mathrm{BMO}$ & & & & & & & 2477 & 3892 & 90 & 4 & 34 & 2 & & 5 & & \multirow{3}{*}{26.04} \\
\hline & RTH & & & & & & & & 27 & 26 & 6 & 21 & & & & & \\
\hline & $\mathrm{AMC}$ & & & & & & & & & 5885 & 1956 & 3495 & 25 & & 15 & & \\
\hline \multirow{3}{*}{ Thursday } & $\mathrm{BMO}$ & & 5 & 2 & & & & & & & 4132 & 7956 & 186 & 2 & 35 & & \multirow{3}{*}{34.44} \\
\hline & RTH & & 1 & & & & & & & & & 47 & 51 & 1 & 14 & & \\
\hline & $\mathrm{AMC}$ & 1 & 9 & 2 & & & & & & & & & 8864 & 998 & 1450 & 2 & \\
\hline \multirow{3}{*}{ Friday } & $\mathrm{BMO}$ & 3 & 14 & 1 & & 2 & & & & & & & & 1366 & 2067 & & \multirow{4}{*}{5.24} \\
\hline & RTH & 2 & 5 & & & 1 & & & & & & & & & 15 & & \\
\hline & $\mathrm{AMC}$ & 39 & 66 & 2 & 1 & 7 & 1 & & & & & & & & & 25 & \\
\hline \multicolumn{2}{|c|}{$\begin{array}{l}\text { Total percent of } \\
\text { conference calls on } \\
\text { weekdays }\end{array}$} & & 7.80 & & & 22.27 & & & 22.38 & & & 38.86 & & & 8.69 & & \\
\hline
\end{tabular}


Table 3: Switching behaviors of earnings announcements and conference calls

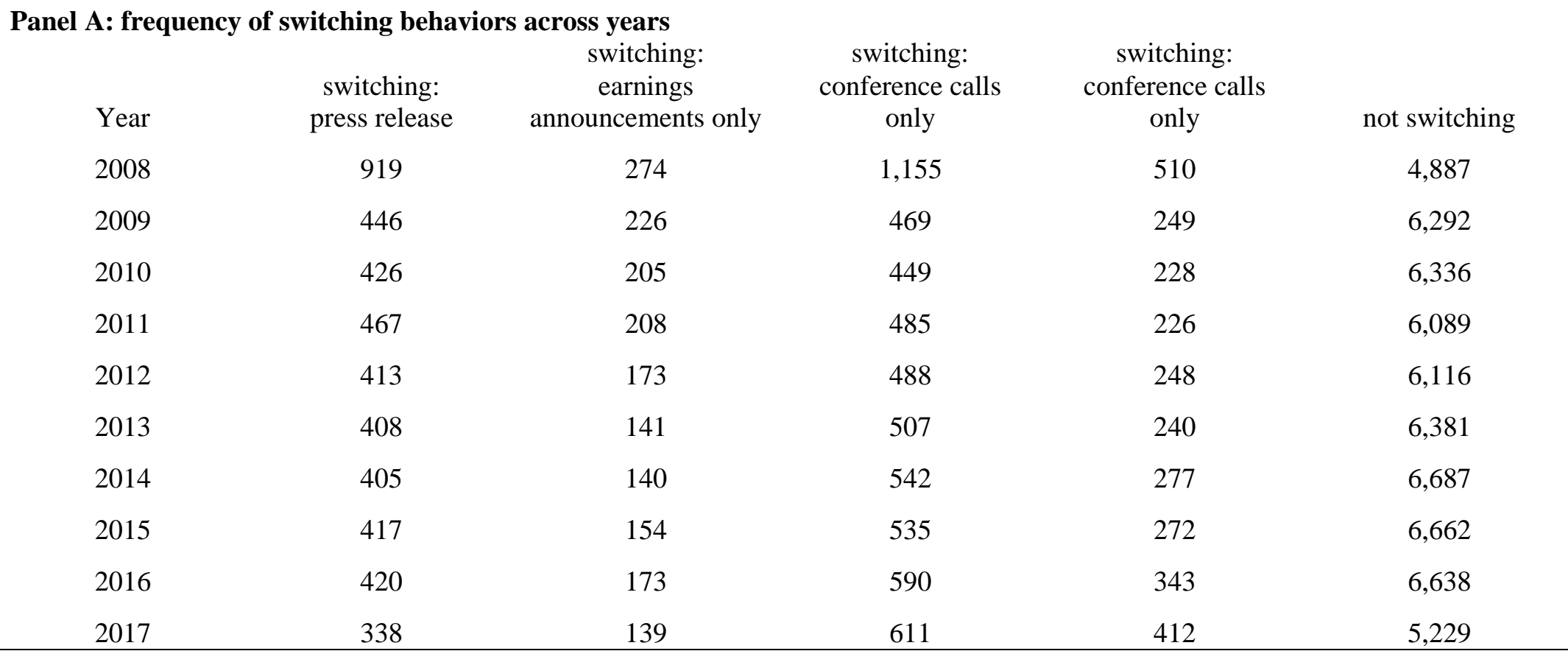

Panel B: frequency of switchers

ever switched the timings of press releases ever switched the timings of earnings calls never switch

Total \# of firms

1,880

2,306

721

\begin{tabular}{|c|c|c|c|}
\hline slot $\quad \operatorname{lag}($ slot $)$ & $\mathrm{BMO}$ & RTH & $\mathrm{AMC}$ \\
\hline $\mathrm{BMO}$ & 14,573 & 1194 & 1061 \\
\hline RTH & 1025 & 26,569 & 661 \\
\hline $\mathrm{AMC}$ & 1071 & 819 & 22,008 \\
\hline$\%$ switching & $12.57 \%$ & $7.04 \%$ & $7.26 \%$ \\
\hline
\end{tabular}


Table 4: Summary statistics

Full Sample (68981)

$\begin{array}{ll}\text { BMO } & \text { RTH } \\ (\text { obs }= & (\text { obs }= \\ 16828) & 28255)\end{array}$

Panel A: information coming out from conf calls

$\begin{array}{llllllllr}\text { Panel A: information coming out from conf calls } & & & & & \\ \text { (1) Earnings Surprise } & 0.023 & 0.011 & 0.056 & 0.009 & 0.013 & 0.050 & 0.030 & -0.111 \\ \text { (2) Tone of FLS } & -0.129 & -0.155 & -0.162 & -0.131 & -0.161 & -0.166 & -0.153 & -0.169 \\ \text { (3) |Earnings Surprise| } & 0.520 & 0.529 & 0.559 & 0.554 & 0.560 & 0.587 & 0.549 & 0.697 \\ \text { (4) |Tone of FLS| } & 0.241 & 0.246 & 0.300 & 0.230 & 0.238 & 0.303 & 0.264 & 0.273\end{array}$

Panel B: general characteristics of conference calls

\begin{tabular}{|c|c|c|c|c|c|c|c|c|c|}
\hline (5) Tone of PrS & 0.685 & 0.623 & 0.597 & 0.674 & 0.620 & 0.588 & 0.622 & 0.606 & 0.631 \\
\hline (6) Uncertainty & 0.016 & 0.016 & 0.017 & 0.016 & 0.016 & 0.017 & 0.016 & 0.016 & 0.017 \\
\hline (7) Len_call & 8.854 & 8.771 & 8.764 & 8.840 & 8.760 & 8.753 & 8.780 & 8.768 & 8.762 \\
\hline (8) Len_PrS & 7.973 & 7.873 & 7.919 & 7.954 & 7.881 & 7.923 & 7.914 & 7.937 & 7.914 \\
\hline (9) AQ Ratio & 2.831 & 2.613 & 2.708 & 2.855 & 2.611 & 2.736 & 2.725 & 2.659 & 2.612 \\
\hline (10) FLS focus & 0.081 & 0.077 & 0.085 & 0.080 & 0.078 & 0.085 & 0.081 & 0.080 & 0.081 \\
\hline (11) \# firm part & 3.358 & 3.330 & 3.229 & 3.352 & 3.336 & 3.243 & 3.305 & 3.406 & 3.358 \\
\hline (12) \# anal part & 7.380 & 6.745 & 6.682 & 7.091 & 6.533 & 6.399 & 6.663 & 6.380 & 6.307 \\
\hline
\end{tabular}

\section{Firm-quarter obs from switchers (46688)} (46688)

AMC

BMO

RTH

AMC

(obs =

15496)

Switching

Switching

from from

switching

(obs $=$

42989)

non-RTH

non-RTH to RTH

$($ obs $=2015) \quad($ obs $=1684)$

18363) (obs =1684) 


\begin{tabular}{|c|c|c|c|c|c|c|c|c|c|}
\hline \multicolumn{10}{|c|}{ Panel C: firm-level characteristics } \\
\hline (13) Actual & 0.007 & 0.009 & 0.000 & 0.006 & 0.009 & 0.000 & 0.005 & 0.003 & 0.005 \\
\hline (14) Size & 7.573 & 7.254 & 6.788 & 7.388 & 7.109 & 6.728 & 7.064 & 7.054 & 6.945 \\
\hline (15) Mtb Ratio & 1.981 & 1.723 & 2.487 & 1.997 & 1.696 & 2.408 & 2.032 & 1.834 & 1.706 \\
\hline (16) Sales Growth & 0.096 & 0.083 & 0.151 & 0.103 & 0.086 & 0.144 & 0.108 & 0.134 & 0.142 \\
\hline (17) Analyst & 2.204 & 2.065 & 2.080 & 2.145 & 2.041 & 2.047 & 2.078 & 2.014 & 1.966 \\
\hline (18) Dispersion & 0.041 & 0.047 & 0.030 & 0.042 & 0.047 & 0.033 & 0.040 & 0.048 & 0.048 \\
\hline (19) Leverage & 1.754 & 1.683 & 1.065 & 1.761 & 1.691 & 1.128 & 1.516 & 1.740 & 1.543 \\
\hline (20) Inst. ownership & 0.771 & 0.724 & 0.709 & 0.769 & 0.719 & 0.709 & 0.732 & 0.681 & 0.686 \\
\hline
\end{tabular}


Table 5: Multinomial logit model - determinants of timing of conference calls

\begin{tabular}{|c|c|c|c|c|c|c|}
\hline & (1) & (2) & (3) & (4) & $(5)$ & (6) \\
\hline VARIABLES & $\mathrm{BMO}$ & $\mathrm{AMC}$ & $\mathrm{BMO}$ & $\mathrm{AMC}$ & $\mathrm{BMO}$ & AMC \\
\hline \multirow[t]{2}{*}{ (1) |Earnings Surprise $\mid$} & $0.079 * * *$ & $0.128 * * *$ & & & & \\
\hline & $(2.68)$ & $(3.30)$ & & & & \\
\hline \multirow[t]{2}{*}{ (2) $\mid$ Tone of $F L S \mid$} & $0.132 * *$ & $0.152 * * *$ & & & & \\
\hline & $(2.13)$ & $(2.64)$ & & & & \\
\hline \multirow[t]{2}{*}{ (3) Earnings Surprise } & & & $0.099 * *$ & $0.198 * * *$ & $0.067 *$ & $0.091 * *$ \\
\hline & & & $(2.55)$ & $(4.38)$ & $(1.61)$ & $(2.24)$ \\
\hline \multirow[t]{2}{*}{ (4) $N D 1$} & & & 0.010 & -0.076 & 0.063 & 0.085 \\
\hline & & & $(0.24)$ & $(-1.25)$ & $(1.11)$ & $(1.08)$ \\
\hline \multirow[t]{2}{*}{ (5) ND1 X Surprise } & & & $-0.158 * * *$ & $-0.272 * * *$ & $-0.146^{* *}$ & $-0.167 * *$ \\
\hline & & & $(-2.68)$ & $(-3.51)$ & $(-2.38)$ & $(-2.01)$ \\
\hline \multirow[t]{2}{*}{ (6) Tone FLS } & & & $0.311^{* *}$ & $0.412 * *$ & $0.109^{*}$ & $0.132 *$ \\
\hline & & & $(2.28)$ & $(2.19)$ & $(1.79)$ & $(1.85)$ \\
\hline \multirow[t]{2}{*}{ (7) $N D 2$} & & & 0.005 & 0.030 & 0.0447 & 0.0218 \\
\hline & & & $(0.09)$ & $(0.39)$ & $(0.73)$ & $(0.26)$ \\
\hline \multirow[t]{2}{*}{ (8) ND2 X Tone FLS } & & & $-0.520 * *$ & $-0.591 * *$ & $-0.194 *$ & $-0.227 * *$ \\
\hline & & & $(-2.32)$ & $(-2.07)$ & $(-1.76)$ & $(-1.99)$ \\
\hline \multirow[t]{2}{*}{ (9) Actual } & $-2.848 * * *$ & $-5.451 * * *$ & $-3.219 * *$ & $-7.380 * * *$ & -1.512 & $-6.274 * * *$ \\
\hline & $(-2.69)$ & $(-3.55)$ & $(-2.51)$ & $(-4.04)$ & $(-1.28)$ & $(-4.02)$ \\
\hline \multirow[t]{2}{*}{ (10) Uncertainty } & -8.267 & $-19.857 *$ & -8.179 & $-19.485^{*}$ & -4.687 & -14.617 \\
\hline & $(-1.19)$ & $(-1.89)$ & $(-1.18)$ & $(-1.85)$ & $(-0.94)$ & $(-1.61)$ \\
\hline \multirow[t]{2}{*}{ (11) FLS Focus } & $3.324 * * *$ & $5.870^{* * *}$ & $3.340 * * *$ & $5.831 * * *$ & $2.324 * * *$ & $1.577 * *$ \\
\hline & $(3.25)$ & $(4.38)$ & $(3.27)$ & $(4.36)$ & $(2.88)$ & $(2.26)$ \\
\hline \multirow[t]{2}{*}{ (12) Size } & $0.152 * * *$ & -0.011 & $0.157 * * *$ & 0.003 & $0.089 * * *$ & 0.081 \\
\hline & $(3.10)$ & $(-0.16)$ & $(3.19)$ & $(0.05)$ & $(2.78)$ & $(1.51)$ \\
\hline \multirow[t]{2}{*}{ (13) Mtb Ratio } & 0.008 & $0.224 * * *$ & 0.009 & $0.225 * * *$ & 0.018 & $0.173 * * *$ \\
\hline & $(0.17)$ & $(3.86)$ & $(0.20)$ & $(3.87)$ & $(0.61)$ & $(3.69)$ \\
\hline \multirow[t]{2}{*}{ (14) Sales Growth } & 0.094 & $0.266 * * *$ & 0.092 & $0.244 * * *$ & 0.056 & $0.246 * * *$ \\
\hline & $(1.55)$ & (3.39) & $(1.52)$ & $(3.12)$ & $(0.88)$ & $(2.82)$ \\
\hline \multirow[t]{2}{*}{ (15) Analyst } & 0.098 & $0.390^{* * *}$ & 0.097 & $0.376^{* *}$ & 0.040 & -0.111 \\
\hline & $(0.93)$ & $(2.64)$ & $(0.93)$ & $(2.54)$ & $(0.61)$ & $(-0.84)$ \\
\hline (16) Dispersion & -1.020 & $-1.778^{*}$ & -0.999 & -1.667 & -0.554 & -0.256 \\
\hline
\end{tabular}




\begin{tabular}{lcccccc} 
& $(-1.38)$ & $(-1.73)$ & $(-1.35)$ & $(-1.63)$ & $(-0.98)$ & $(-0.30)$ \\
(17) Leverage & 0.009 & -0.008 & 0.009 & -0.007 & $0.012 *$ & 0.016 \\
& $(0.98)$ & $(-0.67)$ & $(0.97)$ & $(-0.64)$ & $(1.83)$ & $(1.63)$ \\
(18) Inst. Ownership & $0.581 * * *$ & -0.146 & $0.595 * * *$ & -0.122 & $0.369 * * *$ & -0.257 \\
& $(2.66)$ & $(-0.52)$ & $(2.72)$ & $(-0.43)$ & $(2.63)$ & $(-1.05)$ \\
(19) Constant & $-4.679 * * *$ & $-2.975 * * *$ & $-4.741 * * *$ & $-3.015 * * *$ & $-7.727 * * *$ & $-4.623 * * *$ \\
& $(-5.89)$ & $(-3.65)$ & $(-5.92)$ & $(-3.69)$ & $(-5.52)$ & $(-5.31)$ \\
Observations & & & & & & 46,688 \\
Fixed Effects & 46,688 & 46,688 & 46,688 & 46,688 & 46,688 & Ind \& Year \\
Stickiness & Ind \& Year & Ind \& Year & Ind \& Year & Ind \& Year & Ind \& Year & Ind \\
Pseudo R2 & No & No & No & No & Yes & Yes \\
\hline
\end{tabular}

This table presents the multinomial logit results of the following model with RTH calls as baseline group:

$$
\begin{aligned}
\log \frac{\operatorname{Prob}\left(t_{-} \text {call }=j\right)}{\text { Prob }\left(t_{-} \text {call }=R T H\right)}= & \beta_{0}+\beta_{1 j} \text { Surprise }+\beta_{2 j} N D_{1}+\beta_{3 j} N D_{1} \times \text { Surprise }+\beta_{4 j} \text { Tone FLS }+\beta_{5 j} N D_{2}+ \\
& \beta_{6 j} N D_{2} \times \text { Tone FLS }+\Sigma \beta_{k j} \text { Controls }_{k}+F E+\varepsilon
\end{aligned}
$$

Columns (1) and (2) report the results for the baseline model with unsigned earnings surprise and unsigned tone of forward-looking statements. Columns (3) and (4) report the results for piecewise regression with year and industry fixed effects. Columns (5) and (6) report the results after further controlling for lagged timing to capture the impact of sticky choices. We use year and industry fixed effects. The standard errors are clustered by firm.

***, **, * indicate statistical significance at the 1 percent, 5 percent, and 10 percent levels (two-tailed), respectively. 
Table 6: System equations - determinants of timings of earnings releases and conference calls

\begin{tabular}{|c|c|c|c|}
\hline \multirow[b]{2}{*}{ VARIABLES } & \multirow{2}{*}{$\begin{array}{c}\text { EA - logit } \\
\text { AMC }\end{array}$} & \multicolumn{2}{|c|}{ CC - ordered logit } \\
\hline & & $\mathrm{BMO}$ & AMC \\
\hline \multirow[t]{2}{*}{ (1) Earnings Surprise } & $-0.060 * *$ & $0.071 *$ & $0.102^{* * * *}$ \\
\hline & $(-2.01)$ & $(1.82)$ & $(2.69)$ \\
\hline \multirow[t]{2}{*}{ (2) $N D 1$} & 0.009 & 0.001 & -0.039 \\
\hline & $(0.26)$ & $(0.02)$ & $(-0.81)$ \\
\hline \multirow[t]{2}{*}{ (3) NDI X Surprise } & $-0.068^{*}$ & $-0.122 * *$ & $-0.145^{* *}$ \\
\hline & $(-1.71)$ & $(-2.07)$ & $(-2.24)$ \\
\hline \multirow[t]{2}{*}{ (4) Tone FLS } & & $0.391 * *$ & $0.222^{* *}$ \\
\hline & & $(2.18)$ & $(1.99)$ \\
\hline \multirow[t]{2}{*}{ (5) $N D 2$} & & -0.002 & -0.005 \\
\hline & & $(-0.03)$ & $(-0.09)$ \\
\hline \multirow[t]{2}{*}{ (5) ND2 X Tone FLS } & & $-0.488 * *$ & $-0.211^{* *}$ \\
\hline & & $(-2.18)$ & $(-2.07)$ \\
\hline \multirow[t]{2}{*}{ (6) Actual } & $-2.075^{*}$ & $-3.330 * *$ & $-5.881 * * *$ \\
\hline & $(-1.96)$ & $(-2.51)$ & $(-4.20)$ \\
\hline \multirow[t]{2}{*}{ (7) Uncertainty } & & -6.420 & 10.207 \\
\hline & & $(-0.91)$ & $(1.22)$ \\
\hline \multirow[t]{2}{*}{ (8) FLS Focus } & & $3.361 * * *$ & $4.788 * * *$ \\
\hline & & $(3.24)$ & $(4.45)$ \\
\hline \multirow[t]{2}{*}{ (9) Size } & $-0.316^{* * *}$ & $0.129 * * *$ & $-0.199 * * *$ \\
\hline & $(-7.49)$ & $(2.64)$ & $(-3.43)$ \\
\hline \multirow[t]{2}{*}{ (10) Mtb Ratio } & $0.134 * * *$ & 0.006 & $0.194 * * *$ \\
\hline & $(3.84)$ & $(0.12)$ & $(3.97)$ \\
\hline \multirow[t]{2}{*}{ (11) Sales Growth } & $0.206^{* * *}$ & $0.135 * *$ & $0.279^{* * *}$ \\
\hline & $(4.13)$ & $(2.15)$ & $(4.26)$ \\
\hline \multirow[t]{2}{*}{ (12) Analyst } & $0.337 * * *$ & 0.094 & $0.513^{* * *}$ \\
\hline & $(4.06)$ & $(0.92)$ & $(4.47)$ \\
\hline \multirow[t]{2}{*}{ (13) Dispersion } & -0.012 & 0.009 & -0.011 \\
\hline & $(-1.64)$ & $(0.95)$ & $(-1.33)$ \\
\hline \multirow[t]{2}{*}{ (14) Leverage } & -0.074 & $0.581 * * *$ & -0.095 \\
\hline & $(-0.42)$ & $(2.61)$ & $(-0.42)$ \\
\hline (15) Inst. Ownership & -0.683 & -1.059 & $-1.836^{* *}$ \\
\hline
\end{tabular}


Observations

This table presents the results for the system-of-equations:

$\begin{aligned} \log \frac{\text { Prob }\left(t_{-} \text {release }=A M C\right)}{\text { Prob }\left(t_{-} \text {release }=B M O\right)}= & \beta_{0}+\beta_{1} \text { Surprise }+\beta_{2} N D_{1}+\beta_{3} N D_{1} \times \text { Surprise }+\Sigma \beta_{k} \text { Controls }_{k}+ \\ & F E+\varepsilon\end{aligned}$

$\log \frac{\operatorname{Prob}\left(t_{\text {_call }}=j\right)}{\operatorname{Prob}\left(t_{-} \text {call }=R T H\right)}=\beta_{0}+\beta_{1 j}$ Surprise $+\beta_{2 j} N D_{1}+\beta_{3 j} N D_{1} \times$ Surprise $+\beta_{4 j}$ Tone FLS +

$$
\beta_{5 j} N D_{2}+\beta_{6 j} N D_{2} \times \text { Tone FLS }+\Sigma \beta_{k j} \text { Controls }_{k}+F E+\varepsilon
$$

Columns (1) presents the results for the timing of earnings announcements with base group of BMO. Columns (2) and (3) report the results for the timing of earnings conference calls with base group of RTH. We control for lagged timing of both events to capture the impact of sticky choices. We use year and industry fixed effects. The standard errors are clustered by firm.

$* * *, * *, *$ indicate statistical significance at the 1 percent, 5 percent, and 10 percent levels (two-tailed), respectively. 
Table 7: Market reaction of firms call timing choices

\begin{tabular}{|c|c|c|c|c|c|c|c|c|}
\hline & (1) & (2) & (3) & (4) & $(5)$ & (6) & (7) & (8) \\
\hline & \multicolumn{2}{|c|}{$\operatorname{CAR}(-1,1)$} & \multicolumn{2}{|c|}{$\operatorname{Vol}(-1,1)$} & \multicolumn{2}{|c|}{$\operatorname{Vol}(-1,1)$} & \multicolumn{2}{|c|}{$\operatorname{Vol}(-1,1)$} \\
\hline & \multicolumn{2}{|c|}{ Sample of switchers } & \multicolumn{2}{|c|}{ Sample of switchers } & \multicolumn{2}{|c|}{$\begin{array}{c}\text { Sample of multiple } \\
\text { switchers (number of } \\
\text { switching }>=3 \text { ) }\end{array}$} & \multicolumn{2}{|c|}{ Scheduling close to EA/Call } \\
\hline \multirow[t]{2}{*}{ (1) $R T H t o B M O$} & $-0.002 *$ & -0.002 & $0.057 *$ & $0.033 * *$ & 0.026 & $0.051 * *$ & $0.069^{*}$ & $0.042 * *$ \\
\hline & $(-1.65)$ & $(-1.28)$ & $(1.78)$ & (1.99) & $(1.32)$ & $(2.26)$ & $(1.90)$ & $(2.13)$ \\
\hline \multirow[t]{2}{*}{ (2) RTHtoAMC } & -0.004 & -0.004 & $0.140 * * *$ & $0.120 * * *$ & $0.218 * * *$ & $0.122 * *$ & $0.379 * * *$ & $0.223 * * *$ \\
\hline & $(-1.57)$ & $(-1.52)$ & $(2.63)$ & $(3.21)$ & $(3.12)$ & $(2.54)$ & $(4.26)$ & $(3.76)$ \\
\hline \multirow[t]{2}{*}{ (3) BMOtoAMC } & -0.002 & -0.001 & $0.127 * * *$ & -0.001 & $0.032 *$ & $0.030 *$ & $0.063 *$ & $0.050 *$ \\
\hline & $(-0.81)$ & $(-0.54)$ & $(2.87)$ & $(-0.02)$ & $(1.69)$ & $(1.86)$ & $(1.89)$ & $(1.77)$ \\
\hline \multirow[t]{2}{*}{ (4) BMOtoRTH } & $-0.004 * *$ & $-0.004 *$ & -0.002 & 0.004 & $-0.091 *$ & 0.016 & $0.137 *$ & 0.053 \\
\hline & $(-2.17)$ & $(-1.77)$ & $(-0.05)$ & $(0.16)$ & $(-1.72)$ & $(0.61)$ & $(1.70)$ & $(1.11)$ \\
\hline \multirow[t]{2}{*}{ (5) $A M C t o B M O$} & 0.001 & -0.000 & $0.107 * *$ & 0.016 & -0.013 & 0.006 & $0.130 *$ & 0.003 \\
\hline & $(0.33)$ & $(-0.18)$ & $(2.40)$ & $(0.58)$ & $(-0.28)$ & $(0.20)$ & $(1.85)$ & $(0.06)$ \\
\hline \multirow[t]{2}{*}{ (6) AMCtoRTH } & -0.001 & 0.000 & -0.089 & -0.031 & $-0.136^{*}$ & -0.023 & $-0.250 * * *$ & -0.047 \\
\hline & $(-0.17)$ & $(0.04)$ & $(-1.51)$ & $(-0.78)$ & $(-1.92)$ & $(-0.50)$ & $(-2.59)$ & $(-0.74)$ \\
\hline \multirow[t]{2}{*}{ (7) Size } & -0.000 & $-0.006 * * *$ & $0.502 * * *$ & $0.201 * * *$ & $0.537 * * *$ & $0.167 * * *$ & $0.543 * * *$ & $0.251 * * *$ \\
\hline & $(-0.47)$ & $(-5.51)$ & (29.17) & $(9.25)$ & (20.15) & $(5.28)$ & $(16.60)$ & $(6.20)$ \\
\hline \multirow[t]{2}{*}{ (8) Mtb Ratio } & $-0.001 * * *$ & -0.001 & $-0.093 * * *$ & 0.004 & $-0.093 * * *$ & 0.015 & $-0.046^{* *}$ & 0.023 \\
\hline & $(-5.18)$ & $(-1.31)$ & $(-6.98)$ & $(0.36)$ & $(-4.20)$ & $(0.87)$ & $(-2.07)$ & $(1.24)$ \\
\hline \multirow[t]{2}{*}{ (9) Sales Growth } & 0.001 & $0.002 * *$ & -0.014 & -0.015 & $-0.068^{*}$ & -0.013 & 0.024 & 0.001 \\
\hline & $(0.95)$ & $(2.17)$ & $(-0.60)$ & $(-1.03)$ & $(-1.91)$ & $(-0.64)$ & $(0.73)$ & $(0.04)$ \\
\hline \multirow[t]{2}{*}{ (10) Analyst } & 0.001 & 0.001 & $0.751 * * *$ & $0.277 * * *$ & $0.683 * * *$ & $0.278 * * *$ & $0.694 * * *$ & $0.255^{* * *}$ \\
\hline & $(1.60)$ & $(0.71)$ & (19.08) & (11.07) & (11.02) & $(7.53)$ & $(10.27)$ & $(6.26)$ \\
\hline
\end{tabular}




\begin{tabular}{|c|c|c|c|c|c|c|c|c|}
\hline (11) Dispersion & $\begin{array}{l}-0.009 \\
(-1.44)\end{array}$ & $\begin{array}{l}-0.021 * * \\
(-2.53)\end{array}$ & $\begin{array}{l}-0.226 \\
(-0.67)\end{array}$ & $\begin{array}{l}0.439 * * * \\
(3.20)\end{array}$ & $\begin{array}{l}0.280 \\
(0.53)\end{array}$ & $\begin{array}{l}0.631 * * * \\
(2.97)\end{array}$ & $\begin{array}{l}-1.023 * * \\
(-2.23)\end{array}$ & $\begin{array}{l}0.112 \\
(0.55)\end{array}$ \\
\hline \multirow[t]{2}{*}{ (12) Leverage } & -0.000 & -0.000 & $0.014 * * *$ & 0.002 & $0.015^{* * *}$ & 0.003 & 0.000 & -0.004 \\
\hline & $(-0.36)$ & $(-1.08)$ & $(3.75)$ & $(1.25)$ & $(2.93)$ & $(1.05)$ & $(0.10)$ & $(-1.22)$ \\
\hline \multirow[t]{2}{*}{ (13) Inst. Ownership } & $-0.003 * * *$ & $-0.005^{*}$ & -0.014 & $0.483 * * *$ & $-0.226^{*}$ & $0.356 * * *$ & $-0.280 *$ & $0.436 * * *$ \\
\hline & $(-2.67)$ & $(-1.66)$ & $(-0.16)$ & $(5.86)$ & $(-1.65)$ & $(2.83)$ & $(-1.89)$ & $(3.07)$ \\
\hline \multirow[t]{2}{*}{ (14) Constant } & $0.003 * *$ & $0.043 * * *$ & $7.889 * * *$ & $10.419 * * *$ & $8.027 * * *$ & $10.841 * * *$ & $7.876^{* * *}$ & $9.874 * * *$ \\
\hline & $(2.15)$ & (6.99) & (89.77) & $(78.14)$ & $(54.98)$ & $(57.13)$ & $(60.82)$ & (47.39) \\
\hline Observations & 43,453 & 43,400 & 44,488 & 44,438 & 17,892 & 17,892 & 14,391 & 14,363 \\
\hline Adjusted R2 & 43,453 & 43,400 & 0.605 & 0.842 & 0.620 & 0.845 & 0.562 & 0.804 \\
\hline Fixed Effects & Ind \& Year & Firm \& Year & Ind \& Year & Firm \& Year & Ind \& Year & Firm \& Year & Ind \& Year & Firm \& Year \\
\hline
\end{tabular}

This table presents the results for the market reaction when firms schedule conference calls:

$3-$ day Market Reaction $=\beta_{0}+\beta_{1}$ SwitchRthBmo $+\beta_{2}$ SwitchRthAmc $+\beta_{3}$ SwitchBmoAmc $+\beta_{4}$ SwitchBmoRth +

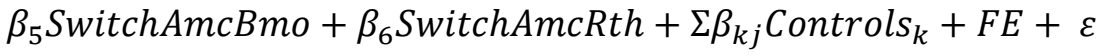

Columns (1) and (2) report the results for the 3-day cumulative abnormal return around the "scheduling" date, calculated by Fama-French 5factors. Columns (3)-(8) report the results for 3-day trading volume around the "scheduling" date. Columns (3) and (4) presents the results for the full sample. Columns (5) and (6) shows the results for the subsample with firms that switch the call timing at least three times during our sample period. Columns (7) and (8) shows the results for the subsample with firms that announce the event schedule within 14 days before the earnings announcements. For each analysis, we use year and industry fixed effects, and year and firm fixed effects. The standard errors are clustered by firm.

$* * *, * *, *$ indicate statistical significance at the 1 percent, 5 percent, and 10 percent levels (two-tailed), respectively. 
Table 8: Correlation of key conference call characteristics

\begin{tabular}{|c|c|c|c|c|}
\hline \multicolumn{5}{|c|}{ Panel A: correlation when earnings surprise is positive } \\
\hline & $\begin{array}{c}\text { Earnings } \\
\text { Surprise }\end{array}$ & Tone of FLS & Tone of $\operatorname{PrS}$ & FLS Focus \\
\hline Earnings Surprise & 1 & & & \\
\hline Tone of FLS & $-0.210^{*}$ & 1 & & \\
\hline Tone of $\operatorname{PrS}$ & 0.063 & $0.124 *$ & 1 & \\
\hline FLS Focus & $0.087 *$ & $0.015^{*}$ & 0.059 & 1 \\
\hline \multicolumn{5}{|c|}{ Panel B: correlation when earnings surprise is negative } \\
\hline & $\begin{array}{c}\text { Earnings } \\
\text { Surprise }\end{array}$ & Tone of FLS & Tone of $\operatorname{PrS}$ & FLS Focus \\
\hline Earnings Surprise & 1 & & & \\
\hline Tone of FLS & $0.254 *$ & 1 & & \\
\hline Tone of PrS & $0.113^{*}$ & $0.095^{*}$ & 1 & \\
\hline FLS Focus & $-0.066^{*}$ & $0.022 *$ & -0.007 & 1 \\
\hline
\end{tabular}

* indicates statistical significance from zero at the 1 percent. 